VII. On the Structure and Development of the Bird's Skull. By W. K. PARKer, F.R.S., F.L.S., \&c. (Part II.)

(Plates XX.-XXVII.)

Read December 16th, 1875.

\title{
INTRODUCTORY REMARKS.
}

IN a paper of mine on the Development of the Bird's Skull (Phil. Trans. 1869, pp. 755807), a single species, the Common Fowl, was used as the subject; this was worked out to as great an extent as was possibje to me at the time.

Year by year since then steady work at other types of the Vertebrata has, by letting in fresh light, shown me some serious deficiencies in that paper, and my mind has not been able to rest without an attempt to superadd something of value to the older piece of research.

I may at once remark that, criticising this my own work, I find that the eye and the hand had done their work better than the mind; the plates are clearer and truer to nature than the descriptions.

The Memoir.which followed that on the Skull of the Fowl treated of this part in the Common Frog, a type so diverse from that of the Vertebrata generally as to mislead me somewhat in my comparisons, and to make me doubt the correctness, of my earlier descriptions. Further researches, however, have set my mind at ease on several points, notably those on the Salmon's Skull (Phil. Trans. 1873, pp. 95-145, plates i.-viii.).

There was another reason, however, why it was desirable to supplement the paper on the Skull of the common Gallinaceous bird, namely, that it is itself a very simple semistruthious type, and conveys but an imperfect idea of the remarkable metamorphoses the Reptilian type of skull can undergo when subjected to the intense life-energy of a highclass perching or climbing bird.

A third reason has acted as a propelling force in this matter : this was a strong desire to clothe with flesh and form the masterly skeleton paper on the "Classification of Birds" given by Professor Huxley to the Zoological Society a few years ago (Proc. Zool. Soc. 1867 , pp. 415-472).

In that paper the palatal structures are chosen as the ground of classification; and although, to a hasty observer, these might seem to be a mere fragment of the whole bird, yet they are, indeed, the parts to which all others follow suit-the upper jaw and palate, the first and part of the second facial arch. To these parts every thing else in the Bird is correlated; they rule, as it were, the whole economy of the Bird.

Renewed researches, which have been zealously followed up by me for some years, on the structure and development of the "trabeculæ cranii," "pterygo-palatine arcades," and nasal labyrinth, have yielded results that seem to me to be of great value.

SECOND SERIES. - ZOOLOGY, VOL. I. 
In this newer work the forms of the Fish and the Reptile have been before my eyes night and day. These have been to me as the larval and pupal stages through which may be traced the changing materials out of which that vertebrate imago, the Bird, is constructed, its hot blood infusing new life and producing unlooked-for transformations.

Now that cranial morphology is beginning to embody itself in a clear and intelligible shape, it may be well to explain the meaning of certain terms that will of necessity be in frequent use.

The term metamorphosis I use in exactly the same manner and for the same purposes as the entomologist, namely, as describing the whole series of changes undergone by the skull or skeleton throughout the life-history of the individual.

The borrowed term isomorphic is used, in a zoological sense, for very similar types in quite distinct groups : the Sun-birds ("Nectariniidæ") may be said to be the isomorphs of the Humming-birds ("Trochilidæ").

The term symmorphic may be used for any morphological part or parts in one type which agree in their structure and development with those of same other types; thus the "Desmognathous" palate of the Parrot and that of the Goose are symmorphic; such agreeing structures are also said to be homologous or representative.

Professor Huxley, in his paper (op.cit.p. 454), places the Goatsuckers and Hummingbirds with the Passerine types, supposing them to have the true "Agithognathous" palate. This is an error : they are Insessorial Schizognaths.

The Woodpeckers ("Picidæe," p. 448) had this service done to them, namely, their vomer was shown to be double, and their maxillaries to have a very rudimentary palatine plate. Thus they could not be treated of as belonging to the Cuckoo tribe ("Coccygomorphæ").

The palatal structures (trabeculæ, pterygo-palatines, and nasal capsules) of the Woodpeckers show that these birds can be classified with none of the groups established by Professor Huxley, as their face is intensely Lacertian and even Ophidian. I have therefore called this group of birds the "Saurognathæ" (Trans. Linn. Soc., Zool. pt. 1, 1875, pp. 1-22, Plates I.-V.).

That peculiarity of the Bird's face which has been termed " Egithognathous" will be explained. It exists in all the "Coracomorphæ" and, besides these, in the Swifts, or “ Cypselomorphæ" (op. cit. p. 468).

The importance of the fact that a low, superstruthious bird like the Hemipod should offer itself as a stock ("phylum") to the half myriad of known Passerines cannot be easily overrated $*$

My principal reason for describing the types of skull presented here is not zoological but morphological. I wish, in some degree, to fill up that which remains over of cranial

\footnotetext{
* On the distribution of "Alectoromorphæ," see Huxley, Proc. Zool. Soc. 1868, pp. 294-319. The Tinamous stand with one foot in that group and with the other over the struthious border, and the larger "Cracidæ" (Crax globicera) and "Megapodidx" (Megacephalon mateo) are "Desmognathous" (see Huxley "On Classification," p. 423, for a figure of the former). Thus the Fowl tribe sweeps over a huge zoological space, immediately overlying the stratum occupied by the "Ratitæ." Amongst the ancient extinct forms of this group we must look in imagination for the forefathers of the Birds of Prey, the Climbers, and the Perchers.
} 
morphology after that of the Fowl has been exhausted, so that the student's conception of the Bird's skull may be richer and more in accordance with the fulness of Nature.

I shall take the present opportunity to give figures of skulls that contain elements frequently spoken of in other papers by me, but not illustrated, such as the "interpalatines" and "mesopterygoids." I shall also have to add other pieces, with their names, namely, the " medio-palatine" and the "palato-maxillary."

Processes that grow in a secondary manner out of the simple facial bars, for union of bar with bar, serially, are called here " conjugational processes ;" the union of the right and left bars of one arch at the mid line is called a "commissure."

\section{Further Researches on the Chick's Sliull.}

My first stage (Phil. Trans. 1869, plate lxxxi. figs. 1 \& 2) is rather underdated as the fourth day; those given are of the fifth, and those soon to be described run nearly to the sixth day. The second stage (figs. 3-13) should be put as dating from the sixth and seventh days of incubation.

One of the first points to be determined in the morphology of the skull is the structure of the "investing mass" of the notochord and the "rafters of the cranium" ("trabeculæe cranii"), the first pair of facial bars.

The figures given in my former paper show the distinctness of these parts much more definitely than I supposed at the time. These I now proceed to explain. At page 758 I speak of the ends of the investing mass as forming the cartilaginous "lingula sphenoidales," thus confusing the free truncated end of the investing mass (plate lxxxi. fig. 2, l.g), which looks forwards and outwards, with the free tops of the trabecular bars, which are better seen in fig. 8 , and in plate lxxxii. figs. $1 \& 3, \mathrm{l.g}$.

The explanation of these parts was made by the exquisitely lucid structures of the embryo Salmon; and now, if these figures of the Fowl be compared with those, it will be seen that the trabecular apices are at first embraced by the squared out-turned ends of the investing mass, and that in the next and third stages the curved trabecular tips, where they surround the pituitary body, open out like the blades of a pair of callipers, and growing more distinct and solid, form, in the third stage (plate lxxxii. figs. 1, 3, \& 4 , $l . g$ ), the free tongue-like cartilages, the meaning of which I for a long while failed to see.

The first figure in the present paper (Plate XX. fig. 1, tr, pn) clears up another very different point, namely, the formation of the "prenasal rostrum," or azygous continuation of the distal part of the trabecular arch.

In my first paper, on the "Skull in the Ostrich tribe" (Phil. Trans. 1866, plate vii. p.n, p. 122), the prenasal cartilage is described as being formed by confluence of the "trabeculæ;" but in the second paper (p. 759) I have corrected this statement, but not without falling into another error, namely, that of supposing the "alæ nasi" to be formed directly out of the "cornua trabeculis." The anomalous position of the parts is caused by the " mesocephalic flexure," the trabeculæ being positively hooked backwards.

The alinasal, aliseptal, and the aliethmoidal cartilages are regions of membrane which chondrify later than, but not separately from, the trabeculæ, the common 
descending nasal septum becoming solid at its sides continuously with the crest that grows upwards from each trabecula. The broadest part of the "trabecular commissure" (Fowl's Skull, plate lxxxi. figs. 1 \& 2, tr) develops into two important structures, namely, the subnasal floor (plate lxxxii. fig. 11, s.v.l) and the conjugational process, which corresponds with the "ethmo-palatine," or orbital plate of the palatine. The subnasal or "supervomerine" laminæ are of small extent and temporary in the Fowl (plate lxxxii. fig. 11, s.v.l); and the conjugational process does not develop into a distant structure, but remains as part of the antorbital wall, its infero-external angle (plate lxxxiii. fig. 5, p.p). In many birds, however, it becomes separately ossified as the "os uncinatum" of Magnus, and takes its place as a kind of transverse bone in the "Musophagidæ" and other " Coccygomorphæ".

In the first of my new illustrations of the Chick's Skull (Plate XX. fig. 1, tr, pn), the down-bent skull of a chick, intermediate between the first and second stages of my former paper, has been sliced off in an obliquely transverse manner, cutting away the fore part of the projecting optic lobes $\left(\mathrm{C}^{2}\right)$ and thalamencephalon $\left(\mathrm{C}^{1 a}\right)$, and removing most of the rudimentary hemispheres $\left(\mathrm{C}^{1 b}\right)$. Underpropping the primary vesicle $\left(\mathrm{C}^{1 a}\right)$ are two thick cartilages, which are severed at their commissure; these are the trabeculæ at their bend backwards. From this position they send downwards an azygous sharp keel. 'This is the nasal cartilage; it looks backwards.

In the next stage ("Fowl's Skull," plate lxxxi. fig. 3, p.n) it is still retral, but has become thick and rounded.

In another section (fig. 2), taken at a different angle to the axis of the head and seen from its front face and not from behind, as in the last figure, the trabecular knuckle has been cut off, and with it the prenasal cartilage. Here the under-placed nasal sacs (ns) are exposed, and the hooked trabeculæe are cut through so as to expose them in section, both in the meso-ethmoidal region above, and under the outer nostrils below.

In this section the fore part of the eyeballs $(e)$ and the hemispheres $\left(\mathrm{C}^{18}\right)$ are cut through; the floor of the nose shows cartilage in it only where the cornua trabeculæ are cut through; the prenasal has been pared off. In this rudimentary nasal labyrinth rudiments of the superior and inferior turbinals $(u t b, i t b)$ are seen, and the membrane infolding them is the early condition of the aliethmoidal and aliseptal cartilages. The eyeball is seen to rest on a very neatly formed ledge; this is the jugo-maxillary elevation; and on the side of this is a lesser ridge, which contains the second preoral bar, the palato-pterygoid.

This palatine bar $(P a)$ is composed at present of indifferent tissue; it is triangular in section, and the ascending crest is its ethmo-palatine region; the conjugational process is correlated to that of the trabeculæ.

In a somewhat more advanced skull, sixth day (figs. $3 \& 4$ ), the eyeballs have been cut through at their middle and the hemispheres at their hindermost part. This belongs to a

* See Dr. Reinhardt's paper, “ Om en hidtil ukjendt Knogle i Hovedskallen hos Turakoerne.” Copenhagen, 1871. In my paper on the "Ostrich's Skull" (p. 158), I referred the "os uncinatum" to the ethmoidal category; but no explanation of its true meaning was had until I saw the secondary bud growing from the outside of each trabecular bar in the Salmon. 
head that had begun to straighten, and nearly comes up to the earliest part of my second stage (" Fowl's Skull," plate lxxxi. fig. 3).

The interorbital septum ( $p e$ ) has here been cut through in the anterior sphenoidal region, and, as in the Mammal, the sphenoidal sinuses (sps) are exposed ; they have not, however, any retral continuation of the nasal wall in a cartilaginous state, and they are very narrow. Below, the strongly compressed trabeculæ $(t r)$ have coalesced, and are now composed of hyaline cartilage; although the commissure is finished below, the crests of the trabecul:e are distinct. These solidify more tardily; and their conversion into true cartilage taking place at the same time as the cranial floor with its double descending keel, there is at present no line of demarcation between these regions.

Afterward (see "Fowl's Skull," plate lxxxiii. figs. 4, 5, \& 11, p.s, o.s) the membranous interorbital space (i.o.s) redivides these dissimilar tracts, leaving for some extent a descending presphenoidal keel and an ascending trabecular crest.

The orbito-sphenoids (figs. $3 \& 4$, os) are small, and lessen rather than increase in size. The palatines are here narrowing towards the pterygoid region.

The next section (fig. 5) is through the optic lobes $\left(\mathrm{C}^{2}\right)$, the pituitary body $(p y)$, and the back part of the eyeball.

The manner in which the face is tucked under the head at this stage makes a most remarkable display of parts possible in one section: these are the apices of the trabecular $(t r)$ and pterygo-palatine arches $(p g)$, and at the same time the distal extremities of the first and second postorals $(m k, c h, b . h y)$. The internal carotid arteries $(i c)$ are seen piercing the fibrous pituitary floor mesiad of the ends of the trabeculæ, the actual apices of which look downwards in the figure. On each side of the high and narrow mouth-roof $(m)$ are seen nearly the whole of the pterygoids $(p g)$; their "trabecular process," or epipterygoid apex, looks a little inwards below, and is seen enclosed in the rudiment of a "soft palate."

The end of each "sphenoidal sinus" (sps) is here seen to reach to the side of the sella turcica. The floor of the mouth $(m)$ contains laterally the Meckelian rods $(m k)$, supramesially the tips of the small distal cerato-hyals $(c h)$, and below the basi-hyal (b.hy). Behind the optic lobes and eyeballs the head has become very narrow. The next section (fig. 6), which has been made through the fore part of the auditory capsules, shows this.

The notochord $(n c)$ lies between the two halves of the investing mass (iv), which has completely coalesced with the periotic cartilage. This section shows the cochlear cavities $(c l)$ and those of the anterior semicircular canals $(a s c)$ with their ampullæ. Below the cochlex are seen the internal carotids (ic), and towards the mid line the submucous tissue is of great thickness; it forms the nidus in which those remarkable ornithic detachments of the parasphenoid, the basitemporals (bt), are developed. All but the fore ends of the mandibular rods are here shown, and also their piers, the quadrates; mesiad of these are seen the basi- and cerato-hyals (bhy, chy).

With regard to the parasphenoid, although it is developed as an azygous bone anteriorly, yet the thick bed of stroma which forms its mother-substance is a symmetricis 
growth from the two sides (see fig. 4), when these masses are approximating below the coalesced trabeculæ.

Before dismissing the chick's skull I have to speak of the posterior conjugational processes connecting the trabeculæ with the next facial bar, the pterygo-palatine.

These parts, the basipterygoids with their articular plate and the corresponding structures in the pterygoids, are thoroughly worked out in my paper on the "Fowl's Skull" (plate lxxxiii. p. 781); but the general morphology, their symmorphism with the anterior conjugationals of the same arch, was not clearly seen.

Before closing this supplemental description of the fowl's skull, I may remark that the fenestra which severs the perpendicular ethmoid from the nasal septum ("Fowl's Skull," plate lxxxiii. fig. 4, c.f.c) is the redifferentiation of the trabeculæ from their surroundings.

In many birds another fenestra, besides the "hinge" and the interorbital space, is found in the nasal septum; and in the Goose tribe a fourth appears between the upper turbinals; to this is added, in Pelecanoides urinatrix, or Petrel, a fifth large fenestra, close behind the antorbitals.

In the adult Swift (Cypselus apus) there are four membranous fenestræ in the interorbital space, instead of two as in Pelecanoides, and one as in Birds generally. This gradual fretting-away of growth-tracts which at one stage of metamorphosis obscure essentially distinct parts is of extreme interest; the highest and, as it were, the imago forms show this most, notwithstanding that they use up and mix together in many ways parts that remain thoroughly distinct in types that may be compared to the pupe and larve. As the two preoral arches are intimately interblended, not only with each other but also with the nasal labyrinth and the cranium, it may be well to set down fairly what splints or secondary bones become applied to or grafted on these arches.

To the hinder pair, the "palato-pterygoids," secondary developments of the mandible or first postoral, there belong the maxillaries, palato-maxillaries, interpalatines, jugals, and quadrato-jugals.

The trabecular arch draws to itself, as subcutaneous or submucous bones, the following-namely, the premaxillaries, septo-maxillaries, vomer or vomers, and the parasphenoid; the "os uncinatum" is an endosteal part.

The splints of the mandibular arch were described in my former paper. The tympanic chain of the Bird is a masked splint-series to the segmented and metamorphosed apex of the hyoid arch.

\section{On the Structure and Development of the Facial Arches in the Passerine types, "Coracomorphæ" (Huxley).}

In the paper already referred to, Professor Huxley has sought to group the flying birds in accordance with the spirit of Humboldt's plant-groups in his 'Views of Nature.' The group under notice, then, is his "Coracomorphæ," or Crow form (p. 469); this is so large that (as my friend Mr. Osbert Salvin informs me) whilst the birds already known and described are about ten thousand, half, or well nigh half, of them belong to this one group. Now the type the skull of which I have already worked out, namely that of 
the Fowl, stands as the head of another group, the "Alectoromorphæ;" and this represents also a broad and goodly family of forms. In another paper, "On the Classification and Distribution of the Alectoromorphæ" (Proc. Zool. Soc. 1868, pp. 294-319), our author has broken this fine family into fragments, separating (see pp. 302-304) not only the Pigeons ("Peristeromorphæ"), which are "Altrices" and have tender young, but the Sand-Grouse also, as the "Pteroclomorphæ," and the Hemipods as "Turnicimorphe." As they stand at present, no cutting and contriving will make the lesser groups, such as the "Charadriomorphæ," "Pteroclomorphæ," and the like, correspond to or in anywise be the equivalents of the great army comprised under the Crow form. Much as I value my friend's paper, I do but consider it in the light of a sign-post to guide others who are footing it on the same road, and not as a finished work to rest in.

In one of the most outlying of the Crow forms, the House-Martin (Chelidon urbica), I have been able to demonstrate the second morphological stage of the second postoral arch. I did not succeed in this point in the Fowl; but now that it is done it will do duty for the whole of the "Sauropsida."

The metamorphosis of this, as of the other arches, has been fully worked out in the "Ichthyopsida," in my researches on the skull of the Frog and the Salmon; but neither of these throw any light upon the long-stalked, trifoliate stapes of the Reptile and the Bird. Professor Huxley, in his paper "On the Representatives of the Malleus and Incus" (Proc. Zool. Soc. 1869, pp. 391-407), says (p. 398), "the suprastapedial cartilage" [he is describing the parts in Sphenodon] "turns out to be nothing more than the proximal end of the hyoidean arch, while the stapes and its appendages are exclusively related to this arch, and have nothing whatever to do with the mandibular arch."

True! and yet he does not say how much of the stapes belongs to the auditory capsule. In the Urodela the stapes is cut out of that capsule, like a bung, and in Batrachia the head of the upper segment of the hyoid arch articulates with the auditory stapes, its uppermost part being segmented off as a "pars orbicularis." In the Mammalia the Batrachia are closely followed (Phil. Trans. 1874, plates xxvi.-xxxvii.). In my former paper on the Fowl's head (plate lxxxi. figs. 5, 9, \& 10,st) I showed, in the second stage, a thick somewhat flattened club of cartilage, the knobbed end of which fitted into the fenestra ovalis, whilst the other or distal incurved end was trifoliate, the upper process being the "suprastapedial " rudiment, the lower the "infrastapedial," and the longer, bowed leaf the "extrastapedial."

In a young Eave-Swallow, at about the same period, the upper end was seen to be continuous with the periotic capsule in front of its fusion with the exoccipital cartilage, and above the outer end of the rudimentary cochlea. This stapedial bar (Plate XX. fig. $7, m s t$ ) has the characteristic curve of the summit of the facial arches, and at this stage has coalesced with the auditory capsule as is the wont of these bars (see the quadrate in continuity with the periotic cartilage, as figured in Huxley's 'Elements,' p. 138, fig. 57, $\left.F^{1} Q u\right)$. This is undoubtedly the second or coalescing stage of the second postoral; it has, however, only coalesced by the strong posterior head; the 
aborted anterior head, comparable to the "tubercle" of a rib, and answering to the short crus of the incus, has been left free. The anterior head, or "suprastapedial" (8.st), is, however, continuous permanently with the auditory capsule in Sphenodon (Huxley, " On Malleus and Incus," p. 397, fig. 4, S.St), and also, as I find, in the Bull-frog (Rana pipiens). Notwithstanding that in Sphenodon the posterior head is free, and the anterior is fixed, contrary to what is here shown in the Chelidon, yet in these two, the adult Lizard and the embryo Bird, the "extrastapedial" (Plate XX. fig. 7, est, and Huxley op. cit. fig. 4, E.St) has a similar shape; even the foramen seen in Sphenodon (a) soon appears in the Bird. The "infrastapedial" (Plate XX. fig. 7, ist) of this young bird is longer than I found it in the Fowl, even after the oval tract of ear-woll had come away with its "mediostapedial" stalk. This is not all; for its pointed apex is continuous with a band of cells of indifferent tissue which runs downwards towards the entering carotid artery at the skull-base.

In Sphenodon (op. cit. fig. 4, Sth) the scooped "extrastapedial" passes directly downwards into a bar which is labelled Sth (stylo-hyal); but in the Crocodile (op. cit. figs. $1 \& 2$, Sth) the stylo-hyal is a short club of cartilage, flattish, with its broad end upwards, looking backwards, and having a clear membranous space between it and the "extrastapedial."

The stylo-hyal of Chelidon answers to this description exactly; and if the reader will turn to Professor Huxley's figure in this part of the Fowl (op. cit. fig. 5, A, B, I.St) he will see that it is there, but that it has become confluent with the infrastapedial. In figs. 5, 9, \& 10, st, of my former paper, this part is not shown; but in a chick one day older (fig. 14, i.st) it is certainly figured, but not distinct. Not having seen it in the earlier stage, I could not choose but find it in the next, as it had then coalesced with the " infrastapedial." In certain birds this part ossifies; and this fact led me to call it the "stylo-hyal" *. The distal part only of the rest of the arch is chondrified, namely, the small cerato-hyal (chy), which, with its fellow, lies in the substance of the tongue. The basal element, "basi-urohyal" ( $b h y, b b r)$, is a stout wedge, which narrows, and then is flat and emarginate behind. The so-called "thyro-hyals" (=1st branchials, $\left.b r^{1}\right)$ are very large, the upper or proximal piece embracing the occiput. In this illustration the lingual skeleton is drawn as flattened out in the minute preparation, so as to display all the parts at once.

I take this opportunity further to illustrate Professor Huxley's account of these parts in his invaluable paper (op. cit. p. 398), and first give the condition of these parts in a fledgling Crow (Corvus corone). The membrana tympani (fig. $8, m i y$ ) is shown from the inner side, with the stapedial and mandibular structures; the articular end of the lower jaw is shown slightly dislocated, and the "siphonium" is cut through.

This tube, the siphonium of Nitzsch, conveys air, not from the quadrate to the lower jaw (see Huxley, op. cit. p. 391), as in the Crocodile, but it directly opens into the tympanic cavity in the Birdt.

* Full often have I argued with the author of the paper just quoted that this dilated, decurved, sometimes bony extremity of the bird's " infrastapedial" was the true "stylo-hyal;" but he always turned his deaf ear towards me. I am silent now ; but " he will rise up at the voice of the bird," so sharp and clear.

+ The dissection here figured was made to dispel a doubt of Professor Huxley's as to the correctness of Nitzsch's 
In the adult of this species, the Carrion-Crow, the siphonium is enringed by the lowest and largest of the seven bones that form the curious tympanic chain. Figures of these have been given in my paper on the "Coracomorphr" in the "Transactions" of thr. Zoological Society.

The stapedial plate $(s t)$, turned a little forward for display, is continuous, as bone, with the mediostapedial ( $m s t$ ), and then come the outspread leaflets of cartilage. The " extrastapedial" (est) is sickle-shaped and broad-backed, its thick convex back being strongly connected with the inner face of the membrani tympani (mty); and the fibres of the perichondrial coat are interwoven with those of the drum-skin itself, and also meet, from without, those of the tendon of the " tensor tympani" muscle (stm).

The tongue-shaped rudiment of the suprastapedial (sst) lies in the base of a twowinged membrane, the fibrous supplement of this part.

The cartilaginous strap running downwards from the extrastapedial to the entering carotid (ic) is the infrastapedial (ist) and stylo-hyal (sth) in one band. The fore end of the mandible $(m k, d)$ shows that, as in the Fish, the mandibular rods do not meet to form a "mentum" in these prognathous types; they keep distinct, and each receives its own dentary.

The form and disposition of these parts in the adult are shown in fig. 9. They are those of the Daw (Corvus monedula); the references are the same as in fig. 8.

In the Crows of the southern world there are many important differences of structure from what is seen in the northern species: notably, the condition of the stylo-hyal is instructive. In the Piping Crow (Gymnorhina tibicen) the general structure corresponds very exactly with that of Corvus; but the stylo-hyal (figs. $10 \& 11$, sth) ends below in a cheese-knife-shaped plate, which lies upon the outer edge of the basitemporal, and is well ossified. Slender as in the mediostapedial shaft ( $m s t$ ), it is pneumatic and communicates with the tympanic cavity by both proximal and distal passages.

Being desirous that this, together with the paper on the Fowl's Skull, should enable the student to form an accurate conception of the skull of the Carinate Bird, as distinguished not only from that of other classes, but also from that of the "Ratitæ," or Struthious order, I now proceed to show some of the most important modifications of the ornithic face. Happily for me, I have at hand a strong and sharply expressed outline of this subject; and now it will be easy to make a more extended study and comparison of the facial morphology of the higher birds (see Huxley's " Classification of Birds," Proc. Zool. Soc. 1867 , pp. $415-472$ ).

My former papers illustrate the "Dromæognathous" face as seen in the raft-breasted Ostrich (Huxley, op. cit. p. 425) and the keel-breasted Tinamou (Phil. Trans. 1866, plates ix.-xv. pp. 113-183); the "Schizognathous" face (Huxley, op. cit.p. 426), as seen in the Common Fowl (Phil. Trans. 1869, plates lxxxi.--lxxxvii. pp. 755-837); and the " Ægithognathæ " have been illustrated in the Zoological Transactions for 1875 *.

I return now to the Sparrow-faced birds, "Egithognathæ" (see Huxley, op. cit. p. 450),

description, as that made the Bird differ from the Crocodile in the disposition of the pneumatic duct. It does differ, as I have shown above.

* See Part I., in vol. ix., plates 54-62. Part II. will soon appear.

SECOND SERIES.-ZOOLOGY, VOL. I. 
The development of the preoral arches and nasal capsule in the "Fringillidæ" (which in the person of the Sparrow gives name to the group) will show the peculiarities of this type, a type which takes in all Professor Huxley's "Coracomorphæ" (op. cit. p. 469), the Swifls amongst his "Cypselomorphæ" (p. 468), and the Hemipods also, which lie down lowly, in an ornithic stratum immediately over the "Tinamidæ" *.

In embryos of the Brown Linnet (Linota cannabina), at about the end of the fifth day of incubation, I find the facial arches and nasal capsules (Plate XXI. figs. 1 \& 2) in a very instructive condition. Nearly the whole of the long " trabecular commissure" is shown, the bar being severed in the prepituitary region, where the ethmoid and basisphenoid meet; the prenasal rostrum $(p n)$ is in full size, as the continuation of the great cartilaginous balk.

This balk is wasting between the ethmoidal and septal regions, preparatory to its peculiar ornithic segmentation.

The open or naturally cloven state of the palate is here shown; for the folds of the nasal labyrinth are well seen below, and the "median nares" (mn) are large and patulous. Neither the true olfactory nor the inferior turbinal regions are displayed in this figure, only the immensely developed alinasal structures, so very secondary in importance and size in the Mammal. The trabeculæe being bowed and folded over in front send backwards, on each side, a flap of cartilage; this may be called the "recurrent fold" $(r c c)$. These two flaps form a commissure below the fore end of the septum nasi; and this becoming ossified from the alæ, sometimes appears as an anterior nasal bridge, a desmognathic band close behind the fore beak (e.g. in Dicholophus).

The posterior of the three folds, the inturned lamina ( $i a l)$, seen in the preparation, is the swelling alinasal wall passing into the floor of the nasal vestibule. Here it is far in front of the maxillo-palatine hook $(m x p)$; but after a short while it will lie on this bony bar, and become intimately connected with it by the binding fibres belonging to each structure. Between the plaits already described is seen a middle cartilage; this is an outgrowth of the wall or posterior plate. It is the alinasal turbinal, and ends in a double free edge.

Although the premaxillaries $(p x)$ and maxillaries $(m x)$ are already well developed, yet one does not see here the broad forked vomer of this type. Looking, however, carefully between the wasting middle bar and the inturned alinasal wall $(i a l)$, there is to be seen at this stage a small oval cartilage; as this appears to me to be as yet undescribed, I propose to call it the "vomerine cartilage" $(v c)$. It ossifies endosteally, and has even now a small core of osteoblasts with the finest deposit of calcareous matter. One of these cartilages is more highly magnified in fig. 2 , and also with it part of the nasal wall, alinasal turbinal, and maxillo-palatine.

This cartilage is small here in the Linnet, but very large, as I shall soon show, in other " Egithognathæ;" and as it forms the mother patch for each vomerine moiety, it

\footnotetext{
* In the paper under notice (p. 459) Professor Huxley placed the Hemipods among the Fowls, "Alectoromorphæ;" but in another equally important contribution to Ornithology, namely, his "Classification and Distribution of the Alectoromorphe" (Proc. Zool. Soc. 1868, pp. 294-319), he places the Hemipods apart, haring gained a clearer insight into their peculiar characters (see p. 304). They are now his " Turnicimorphæ."
} 
is of great interest, and is new to me. If any morphologist knows what it answers to in the lower vertebrate types it were well that he should explain it*.

As the metamorphosis of these parts is very rapid, it is necessary to examine embryos not more than a day or so in advance of or behind each other. In no longer a period, what is displayed in fig. 1 is exchanged for what $I$ have shown in fig. 3. Here the small osseocartilaginous nuclei have developed into the large ox-faced vomer, with its broad anterior part grafted on each side upon the alinasal wall, which turns directly inwards, and spreads in a pedate form to apply itself to the vomer. On one side of the V-shaped emargination the vomerine piece is fenestrate; the bony matter here becomes detached, and an additional bone formed. This additional bone is seen in the fledgling (see it in the young Sparrow, fig. 4, smx). Not only does the vomer grow into the nasal wall, but the alinasal turbinal (fig. $3, a t b$ ) also; hence the huge size of the upper vomerine groove, which is so striking in the Crow tribe ("Corvidæ" proper); for the thick common end of the wall and the turbinal approach the septum nasi, and, rising high on each side, embrace the base of the septum. Another noteworthy characteristic of the Passerine face is the elbowed form of the palatines near their hinder third; this out-bent part does not ossify " by first intention," but lingers until it is solid hyaline cartilage, and then receives its own endosteal centre. This new bone is an arrested " transverse" element, my " transpalatine" (tpa).

That part of the Passerine palatine which is arrested from forming a bony palatal floor generally exists as a free fore-looking spine. This is well seen in the Sparrow (fig. 4, ipa); it is the "interpalatine process." In Ducks and Swans this is a separate knuckle of bone; and in looking over a large number of Starlings' skulls, I find it in certain of them (see Plate XX. fig. 12, ipa).

Other parts of the Passerine face must be noticed ; but I turn now to the most striking condition of the vomer. I have hitherto found in the group: it is seen in the native Wren (Troglodytes vulgaris). When the whole palate of the bird is viewed (Plate XXI. fig. 5, v), the vomer is seen to be as large, relatively, as in the "Ratitæ;" but its anterior third is composed of true cartilage. In a spirit-specimen, by careful dissection, I have been able to make out what is shown in fig. 6 on a larger scale. Here one of the palatines $(p a)$ and both of the maxillo-palatine hooks are removed; they are, however, indicated by a dotted outline.

\footnotetext{
* Finding the development of the Passerine "vomer" so totally unlike what I always supposed, namely, that it is an endosteal ossification of cartilage, my mind cast about for some symmorph in the cold-blooded types and in the Reptilian birds (Ratitæ). I had not far to seek; for lying unexplained in my memory were certain structures in the Snakes and also in the struthious Rhea, which I had figured years ago (Phil. Trans. 1866, plate x. fig. 14, the alate cartilages above $v$ ), but which had hitherto resisted all efforts at explanation. On reexamination of these parts in the Rhea chick, I find that they are free cartilages in the maxillo-palatine region, and attached to those processes and to the fore forks of the double vomer by fibrous tissue. In tho Snake the nasal glands and their bony capsules, the vomers and septo-maxillaries $(P)$, are flanked on their outside by an arcuato-spatulate flap of cartilage, continuous by a narrow stalk with the recurrent laminæ, or separate from that process, both states occurring in the same skull. As in the furculum of the same bird (Linota, see "Shoulder-girdle and Sternum," plate xv. figs. 12-15), the Linnet's "vomer" is a morphological compound, and the counterparts of its componont elements are persistently separate in the cold-blooded types.
} 
Part of the bialate septal base (tr) and part of the nasal labyrinth of one side is here shown. We here see that the trabeculæ have only partially lost their flatness, and form a partial subnasal floor, and that the alinasal wall (nw), after giving off the "alinasal" turbinal ( $a t b)$, ends externally in a blunt process, and internally in an incurved bifurcate $\operatorname{rod}(i a l)$.

The forks of this rod are continuous with the corresponding vomerine half; the halves of the vomer are joined by a long commissure into a flat bone, notched at both ends; the long posterior ends articulate with the ethmo-palatines, and the shorter anterior forks pass into a cartilage shaped like a breast-plate. This plate, being gently emarginate behind, forms a fenestra with the help of the bony vomer; it narrows gently forwards, and ends in a pair of straight styles.

This plate is nothing more or less than a forward continuation of the vomerine cartilages $(v c)$, the unossified parts being bridged over by a commissure. For relative size, these vomerine cartilages* have their rivals only in the Snake, the Rhea, the Hemipod, and in certain low-typed Passerines of the southern world (Notogaa), namely, Ancretes parulus, Pipra auricapilla, and in that remarkable type Pachyrhamphus.

Other characters in the Wren's face are of importance, as illustrating what is commonly found in the numerous related forms.

The lacrymal (fig. 7, l), often absent, is here very small; the lateral ethmoid (eth,pe), on the other hand, is very large, and shows itself on the upper view; its inferior angle is separately ossified as an "os uncinatum" (ou), or palato-trabecular conjugational bone.

Between and below the eyes the trabecular crested bar $(t r)$ has been freely differentiated from the ethmo-presphenoidal bar ( $p e$ ), and the long overlapping process of the pterygoid has become segmented into a distinct "mesopterygoid" (ms.pg), soon, however, to ankylose with the palatine. In this rather young bird the transpalatine (fig. $5, t p a$ ) was scarcely confluent with the broad part of the long and slender palatine $(p a)$. The delicate pterygoids (fig. 5, $p g$ ) here are more like the epipterygoid of the Lizard than its pterygoid; but the terminal part (apex of the bar) is alone upturned. This upturned part is very long in some "Coracomorphæ"-e.g. Coccothraustes, one of the most specialized of the conirostral division of the group. In certain subfamilies of the "Coracomorphæ," although the maxillo-palatine processes do not solder the upper jaws together, yet the palate is made more solid by means of an additional bony wedge, the " palato-maxillary ;" this grows in between the prepalatine bar and the body of the maxillary. In the "Cardinalidæe" (Plate XX. fig. 13, pa.mx) it is a large and thick bone; it is somewhat smaller in the Buntings (Emberiza, Plectrophanes, Phrygilus), and also somewhat smaller still in the "Icteridæ," "Sylvicolidæ" (Mniotilta, Dendroeca, Trichas, Chlorophanes), and in the "Tanagridæ" (Tanagra, Prionocheilus, Stephanophorus).

That curious bone, the "os uncinatum," the matrix of which was first developed as a conjugational bud from the trabecula, is very large in the Grosbeak (Coccothraustes), as in its elimbing isomorphs the Parrots. The "posterior conjugational processes," "basipterygoids," and their counterparts on the pterygoid bones are early arrested in the

* If the Wren had possessed a "recurrent alinasal," like the long forked one of Vireosylvia olivacea, the two subseptal floors would have reached each other. 
"Coracomorphæ;" spiny rudiments, however, are not seldom seen, especially in southern forms, as, for instance, Gymnorhina, Homorus, Dendrocolaptes, but most clearly of all in a form allied to the Sun-birds, namely Anthreptes malaccensis.

I have purposely mentioned these modifications of the face in the very numerous types of the Crow form, and if it hat been possible I should have sought to make the " Egithognathæ" run parallel with the "Coracomorphæ;" but Nature herself forbids this. Yet it is some gain to have been able, as Professor Huxley has done, to take in a lump nearly half of the myriad of known birds, to show that all these are " Fithognathous," and to call them by the name of the commonest and yet one of the highest of the group, namely, the Crow. Here the zoological group cannot be made to hold all the morphologically agreeing types, the "symmorphs." This will be felt still more strongly in the next group to be considered, the "Coccygomorphæ" (Huxley, op. cit. p. 466), which, with an extension of its boundaries to be proposed here, will contain " Egithognathæ," "Schizognathæ," and "Desmognathæ."

To make the matter a little clearer, it is necessary to show that there are several varieties or degrees in the morphological types of the ornithic palate, as designated by Professor Huxley. In the " Egithognathous" palate I find three varieties, namely :-
a. Incomplete.
b. Complete: var. 1.
c. Complete: var. 2.
d. Compound.

a. Incomplete " Egithognathism" occurs in the "Turnicimorphs," Hemipodius or Turnix. Here the vomerine cartilages are very large and incompletely ossified, and the broad double vomer has a septo-maxillary at each angle; but these bones are only strongly tied to the " alinasal" cartilage, and do not graft themselves upon it.

b. Complete: var. 1. This occurs in some of the lowest harsh-voiced "Coracomorphæ." The vomers are developed in large "vomerine cartilages," which they often only partially ossify; but these osseous tracts are distinct from those of the often bony alinasal walls and turbinals : a small septo-maxillary on each side generally appears, limpet-like, on the angle of the alinasal inturned cartilage, but does not run into it. This is well seen in Pachyrhamphus, Pipra, and Thamnophilus.

c. Complete: var. 2. This occurs in an immense group, comprising most of the "Coracomorphæ" and also the Swifts ("Cypselidæ"); here the vomerine bones are grafted upon the nasal wall, and thus the bird loses its primary schizognathism.

d. Compound. This type occurs where, in a perfectly ægithognathous face, desmognathism is produced by ankylosis of the inner edge of the maxillaries with a highly ossified alinasal wall and nasal septum.-Examples, Gymnorhina tibicen, Paradisea papuana, Artamus leucorhinus. Of this type a feebler form is produced when the maxillaries only coalesce with the ossified alinasal wall, as in Dendrocolaptes albicollis, Thamnophilus doliatus, and Phytotoma rara.

For Professor Huxley's account of the Desmognathous palate, I refer to his paper (p. 485). I have one remark to make, namely, that the vomer is very broad anteroinferiorly (as in the Chelonia) in the most perfectly desmognathous Raptorial palate, 
that of the "Falconidæ," also that the vomer is not small in the "Ardeidæ" and Spoonbill, but very large; it is primarily double in them, but mostly single in the "Coccygomorphæ " (when present) and in the "Chenomorphæ." In the gallinaceous "Schizognathæ" the vomer is azygous ; in the charadrians it is double.

The varieties of the Desmognathous palate are four, namely :-

a. Direct, as in Falcons and Geese, when the maxillo-palatines meet below at the mid line, as in the mammal. Two subvarieties of this form occur-in the Falcon, where the nasal septum is ankylosed to the hard palate, and in the Goose, where it remains free.

b. Indirect. This is very common, and is best seen in Eagles, Vultures, and Owls; the maxillo-palatines are ankylosed to the nasal septum by their inner margin, but are separated from each other by a chink. This is well seen also in the fledgling of the Falcon, which is indirectly desmognathous at that early stage.

c. Imperfectly direct. This is where the maxillo-palatine plates are united by harmony-sutures, and not by coalescence. Example, Dicholophus cristatus.

d. Imperfectly indirect. Here the maxillo-palatine plates are closely articulated with and separated by the median septo-maxillary, but there is no ankylosis. Example, Megalama asiatica.

e. Double desmognathism. A fifth variety may be added in such a case as Podargus, where the palatines as well as the maxillaries largely coalesce below; to a less extent this is seen in the gigantic species of the Hornbills, e. g. Buceros birostris (see Huxley, op. cit. p. 446, fig. $28, P l)$.

Having thus analyzed their morphological characters, we shall be better able to determine their zoological value. Although my proper business in this paper is the determination of purely morphological meanings, yet I venture to offer these to the zoologist embarrassed with the dazzling variety of types.

On the Structure and Development of the Face in Cuculine Birds.

After the many hundreds of the "Coracomorphr" have been set aside, there yet remains a large residuum of high-class " Arboreal birds."

Some of these are easy to cull from the rest, as they "pass under the hands of him that telleth them," without any confusion. Such are the Pigeons; such also are the Parrots; and the two "Families" of the Woodpeckers stand apart. A legion, however, of other forms follow; these, for convenience" sake, may take their group-name from the Cuckoo, e.g. " Coccygomorphæ."

Professor Huxley's "Cypselomorphæ" (op. cit. p. 468) is his worst group; and he has evidently tied its subdivisions together under some degree of misconception of their palatal morphology. Trochilus has not " a true Passerine vomer" (op. cit. p. 454), and neither this bird nor the Goatsucker is Agithognathous: Cypselus is, however; and yet, lying close by the true Swallows ("Hirundinidæe), it differs in many most important particulars from them, having no singing-muscles, no cæca coli, and is possessed of organs of flight very similar to those of the Humming-bird.

In fundamental cranio-facial mornhologv the Swifts are most Coracomornhous. and 
the Goatsuckers least: the Goatsucker, agreeing in very important characters with Podargus and Steatornis on the one hand, and with the Trogons on the other, lies altogether on a lower and more embryonic level than the "Coracomorphæ," especially those to which the Swifts are allied. These other "Families" may take their place for the present with the other equally discordant "Coccygomorphæ," and the term "Cypselomorphæ" be allowed to drop. The Swift, so far as its cranio-facial morphology is concerned, is an "Egithognath," and I have treated of it in a paper which has been read at the Zoological Society. The Goatsucker and Humming-bird come under the plan of the present memoir.

\section{On the Structure of the Face in Caprimulgus europæus.}

The moth-shaped mouth of the Fern-Owl is roofed in in a manner peculiar to itself; but its gaping face is developed by a process in nowise different from that which operates in its nearer or more distant relations.

In the basal figure (Plate XXI. fig. 8) the trabecular structures are largely hidden by the palatines ; and to understand this most frog-like of all the skulls of the "Carinatæ," the student must examine the actual object.

Bony matter is here spun to its uttermost degree of fineness, and the resulting substance is something more like feather than bone. The whole shape is flattened and outspread, and, as in the Batrachia, the originally flat broad trabeculæ have retained much of their primary form. In front, however (Plate XXI. fig. 8, and Plate XXII. fig. $1, s n$ ), they are narrowed, and quite absorbed anteriorly, as in all other birds; at least, the azygous prenasal outgrowth is early absorbed. Behind, the bony trumpets that grow from the ossifying apices of the trabeculæ spread far apart, forming the "anterior tympanic recesses" (atr), and enclosing the V-shaped double Eustachian tube $(e u)$.

The trabeculæ, as they surround and converge in front of the pituitary body, are converted into a broad and winged mass of bone by the parasphenoid (pas), and at each side of the common Eustachian opening there are two "conjugational processes" (fig. 8, bpg). The lower of these is the "basipterygoid" proper, and it carries the free cartilaginous plate for pterygoidean hingement; this flat broad process looks forward. Above this is a retral hook, which merely holds a ligament.

As in the Frog, the trabecular and parasphenoidal structures project but little below the lateral ethmoids (Plate XXI. fig. 8, $p p$ ), so that each pars plana seems to grow out from the median, beam-like, large-winged outgrowths : they have carried the "palatine conjugational process" (ou with them. This does not ossify into an "os uncinatum," as is common in the "Cuculinæ," but remains persistently soft as hyaline cartilage.

In front, between these ecto-ethmoidal wings, the broad parasphenoid and the trabecular base of the meso-ethmoid each separately taper to a point; and here the first facial arch has part of its long commissure absorbed to form the cranio-facial hinge.

In the pin-feathered nestling the trabecular base of the septum nasi (Plate XXII. fig. $1, s n)$ is rather solid, but the azygous rostrum has been already absorbed. In the adult (Plate XXI. fig. $8, s n$ ) the "posterior septal bone" is rather solid than spongy, and 
its edges can be seen in an upper view (Plate XXI. fig. 10) projecting beyond the nasal processes of the premaxillaries and upper spur of the nasals, and in the lower view (fig. 8) above and in front of the vomer. But the rest of the trabecular part of the septum nasi is absorbed, and only its nasal part is retained; it is bony, and the bony matter passes a short distance into the paired "alæ" (figs. 8 \& 10). As to the secondary or splint-bones of the trabecular arch, I have already spoken of the parasphenoid: the others are, in this case, the premaxillaries and the vomers. The former (fig. 8, $p x$ ) appear very small on the lower surface, but above (fig. 10) each half is seen to be equal to the corresponding maxillary, and to overlap it, as in birds generally and Teleostean Fishes. The dentary margin, however, does not reach nearly so far back as in birds generally, and this double bone is ornithically very small.

The other double bone is the vomer. This is a long bar of spongy bone, rather bluntly pointed at the fore end and sharp behind (figs. $8 \& 9, v$ ); it is quite distinct from the overlying ethmo-palatal bars in newly fledged birds (fig. 9); but in the adult (fig. 8) it becomes a derived commissural band to the palatine arch, as in a large number of birds, notably the " Coracomorphæ."

Flat above, where the palatal bars lie upon it (fig. 9, v, epa), the vomer is carinate below throughout its entire length (fig. 8). In the younger (pin-feathered) fledglings I found the vomers distinct throughout their whole length (Plate XXII. fig. 1, v). They were long styles, approximating very closely in front, and gently diverging behind. They were seen to have been formed by ossification of a fibrous and not a cartilaginous tract. In more mature fledglings the fore ends had united (Plate XXI. fig. 11, v), and the hinder ends were still more divergent. These again approximate, ankylosis takes place thoroughly fore and aft, and the inferior surface ossifying, the interpalatine "raphe" acquires its long keel. The fore end of the vomer in the adult (fig. 8) becomes rounded, losing the beaked form it had in the newly fledged bird (fig. 9), and at this part below the maxillo-palatine hooks $(m x p)$ are notched on their inner margin to articulate with this extremity of the vomer. A character like this gives the palate a very " Egithognathous" appearance, as this curious articulation, which bridges over the chink on each side, is often seen in southern "Coracomorphæ," both those of low and also of a high type, as in Grallaria, Thamnophilus, Dicrurus, Dendrocolaptes, Homorus, and Gymnorhina. But I have already said that these vomers are membrane bones; and I here show, in three stages, the longish ligament which binds the vomer to the internal alinasal wall with its long worm-like turbinal (Plate XXII. fig. 1, and Plate XXI. figs. 9 \& 11, $a l n, v)$. In the second of these three stages (fig. 11), the inturned alinasal wall is seen to lie on the broad maxillo-palatine; but it stops far short of the vomer, which also fails to spread its shoulders towards the cartilage.

The palatine arch of the Fern-Owl equally departs from the Coracomorphous type, and eleaves to what is signally Cuculine-I mean, in the broad sense of that word.

It has been already shown that the distinctively Passerine or Corvine character of the palatine is the metamorphosis of the primary bar into four pairs of true morphological endoskeletal elements, to say nothing of the secondary bones. But in Caprimulgus, my youngest specimen (Plate XXII. fig. 1) only shows a trace of true cartilage on the edge 
of the overgrown "transverse" region; and the first and only palatine centre runs riot over both morphological territories. Also in the hinder division of the arch-moiety the pterygoids correspond to those of the young nestling, but not to those of the fledgling Passerine; for each pterygoid sends a spike-shaped process over the palatine; but this does not become a "mesopterygoid" bone (Plate XXI. fig. 11, and Plate XXII. fig. 1, pg).

The lower fore-looking spines of the palatines do not increase much in size-compare the "interpalatine" of the young (Plate XXIT. fig. 1, ipa) with those of the adult (Plate XXI. fig. 8). But the upper or orbital processes, the ethmo-palatine bars, grow exceedingly, and meet by suture at the mid line (compare Plate XXI. figs. 8, 9, \& 11, epa). This apposition is a step towards a true facial " commissure." The palatines are elegantly bowed outwards from each other behind this tract, and then form a complete commissure, like that of the trabeculæ (Plate XXI. figs. $8 \& 9$ ). By the time this bird is fully fledged the posterior palatal region is joined together at the mid line by a cartilage common to both sides, and this cartilage becomes ossified by two endosteal centres; these I propose to call the anterior and posterior "medio-palatines" (Plate XXI. figs. $8 \& 9, m p a)$. Now the morphologist, at first "rounding about in darkness," feels himself safely within the great Cuculine territory, knowing that there and amongst the "Celeomorphous" tribes (Picidæ) this structure is alone to be found *.

With regard to the articulation of the pterygoids with the basipterygoid processes $(b p g)$, Caprimulgus is countenanced by many types within the great Cuculine circle. I see them everywhere in smaller or larger rudiments; but they are perfect in a very near relation, the Oil-bird (Steatornis), and also in the Trogons and Humming-birds.

There are but two pairs of palatine splints, the maxillaries and jugo-quadrato-jugals $(m x, j)$; the latter are mere curved needles of bone; the former are elegantly ornithic pieces, with, however, characters that are peculiar to this bird. In the young (Plate XXI. fig. 11, and Plate XXII. fig. 1, $m x$ ) the maxillary differs but little from that of Struthio camelus ("Ostrich Skull," plate viii. fig. 2, and Huxley, "Classification of Birds," p. 420, fig. 1, Mxp); for the palatal plate is rough, large, and 4-sided, and the cuneiform body of the bone is very similar with its zygomatic process. In the adult, however (Plate XXI. fig. 8), the change is as though the most delicate chiselling had been fining it down into a very Passerine element; the maxillo-palatine hooks especially might belong to a southern Crow. The bone has its own caprimulgine diagnostic in an f-shaped fore-turned spur, which is applied, for defence, to the nasal wall on each side (Plate XXI. fig. 10, np.mx). The figures show how thoroughly non-passerine is the nasal labyrinth (Plate XXI. figs. $10 \& 11$, and Plate XXII. fig. 1, aln, als, atb, itb); the upper view (fig. 11) shows, through the transparent tubular nostril-walls, the alinasal turbinal (atb), which is exposed in the inferior view of the younger specimen. The inferior turbinal $(i t b)$ is similarly displayed in the two figures, its line of insertion being seen from above, and its anterior half is shown in the lower view (Plate XXII. fig. 1, itb). I have already described the relation of the nasal wall to the vomer, and have only to

* I am well aware that in the larger Grallæ, Mycteria, Baloniceps, Ciconia, \&c., and the "Totipalmatæ," the palatines form a bony " commissure;" but there is no key-stone in their palate. In the Pelicans this common bar sends upwards a crest which is the symmorph of the trabecular crest.

SECOND SERIES.-ZOOLOGX, VOL. I. 
add that the upper and middle turbinals are not more developed than in the common Fowl. The small nasal septum (sn), diminishing forwards, is the only part ossified in front of the hinge, the bone running a little into the alæ; and also in the true olfactory region the root of the simple aliethmoid alcoil is alone ossified; and this growth comes directly from the perpendicular wall, or meso-ethmoid. The lachrymal (fig. $8, l$ ) is a large spongy bone, broad in the roof of the skull, pedate where it binds upon the zygoma; and it entirely excludes the lateral ethmoid from the upper and outer regions of the face. This is a Cuculine character.

\section{On the Structure and Development of the Face in the Humming-birds ("Trochilidæ").}

Professor Huxley (op. cit. p. 454) says "Trochilus has the true Passerine vomer, with its broad and truncated anterior and deeply cleft posterior end. I have not yet been able to obtain a perfectly satisfactory view of the structure and arrangement of the palatine bones in the Humming birds." That same paper contains several figures drawn from his friend's preparations; and I wish those which could have been supplied to him of the Humming-bird's skull had been used by him also; they would have prevented the error contained in the above quotation. I have been long familiar with these parts in the old and nestling bird, in specimens from Barbadoes (? Lampornis); and now I am able to add the structure of the largest known species, from the Andes of Peru (Patagona gigas) *.

It might have been supposed that the Humming-bird would have been especially related to its "Tenuirostral" isomorphs the Sun-birds ("Nectariniidæ") and their allies; but I find nothing in these, except extreme prognathism, which indicates any special relationship. Having carefully dissected and drawn several scores of Passerine types, to say nothing of the Cuculines over the border, it seems to me not altogether a difficult task to weigh and measure the relationships of these bright "minims" of vertebrate life. No isomorphism apparent in types that grow from the uppermost twigs of the life-tree should satisfy the ornithologist in matters of affinity; down by the root must morphological observation be commenced. I had hoped to find the Trochiline congeners in southern-world forms, such as Nectarophilus and Anthreptes, from Celebes, or in the Australian genera Acanthorhynchus and Ptilotis; but such is not the case. Morphologically-I do not say zoologically-I am nearer my starting-point down among the superstruthious Hemipods, and the Passerines that have sprung up from that low level, such as Pipra, Pachyrhamphus, and Thamnophilus.

All this is said in relation to Passerine modification, as such ; not as seeking to lower the idea of the specialization of the Trochiline type, which is without rival. These zoological ideas force themselves forwards; but my work is with the morphology of the region of the face.

\footnotetext{
* The old and young specimens came to me, the former in spirits, the latter dried in a letter, from my friend the Rev. Jno. Philp, for several years missionary in that island. The gigantic form, also a spirit specimen, belongs to my excellent co-worker in this field, Professor Alfred Newton, F.R.S.
} 
The forth-drawing (prognathism) of the facial bars has been carried to its uttermost extent in the Humming-bird; but the secondary parts of the trabecular arch occupy two thirds of the length anteriorly, their endoskeletal axis or prenasal rostrum early undergoing absorption. Behind, the apices of this arch are buried and lost in the outworks of the tympanic cavity; and below, just in front of this part, the great splint, the parasphenoid, marks the bowed converging bars (Plate XXII. figs. 2, 3, 4, 8, pas). Here, just outside the common Eustachian meatus (eu), the trabeculæ have sent out conjugational spurs, with their obliquely fore-looking facets for the pterygoids.

This high form gives us the extreme of a series commenced in the Struthionidæ, where the hinder end of the pterygoid is wedged in in the Emu between the quadrate and basipterygoid process. Even in some "Ratitæ" (see "Ostrich Skull," plates vii.-xiv.) the articulation is further forwards, whilst the series is obtained by passing to the Tinamou (plate xv.), the Syrrhaptes (Trans. Zool. Soc. 1863, vol. v. pl. xxxvi. fig. 1); then come the Plovers, Pigeons, Owls, \&c., where it is in the middle; the "Alectoromorphæ" and "Chenomorphæ," where it is at the anterior third; and, lastly, here in the "Trochilidx" it is quite at the fore end. Of necessity, this relative motion, as it were, of the palatine on the trabecular arch is attended with shortening of the basipterygoid processes as we pass along the series from the Emu to the Humming-bird. The trabecular base of the meso-ethmoid (Plate XXII. fig. 3, pas) is short, broad, pointed, and keeled in front; and the hinge between this part and the septum nasi is finished by uncleft cartilage above (Plate XXII. fig. 4, eth, sn). The remainder of the trabecular bar is one with a most small true nasal septum; there is a larger posterior and a smaller anterior osseous centre in this small cartilaginous keel (fig. 4, sn). There are several secondary bones applied to the trabecular arch besides the hinder plate, or parasphenoid. In front the premaxillaries $(p x)$ take the lead; they are here at their highest development ; they reign in this type, especially, and all things else in the organism are in conformity with them.

In the old bird (fig. 2) the premaxillaries are three fourths the length of the face; in the nestling (fig. 8) they are only two thirds; so that it is evident that this excessive prognathism takes place by the working of a general morphological law.

The boundaries of this double bone are best seen in the young (fig. 8); the dentary processes $(d p x)$ nearly reach the maxillo-palatines $(m x p)$ behind, and the palatine processes (figs. $8 \& 9, p p x$ ) are the twentieth of an inch shorter; as usual, the nasal processes (fig. 5, npx) are strongly grafted on and ankylosed to the forehead. Laterally the upper and lower portions of the premaxillaries are thinned out extremely, and present ragged edges towards each other: this can be seen in the lower view (fig. 2). The halves of the vomer are thoroughly fused together in my young specimen (figs. $8 \& 9$ ); they show no sign of being formed on any thing else than a tract of fibrous tissue, and their likeness and dissimilarity to the true Passerine vomer is well shown.

The long anterior spike in which the coalesced pieces terminate in front would not of itself exclude them from the " Egithognathæ;" in the typical Chough (Fregilus graculus), and in the aberrant Lyre-bird (Menura superba), the double vomer is blunt-pointed in front; but in them, supero-laterally, the scars are seen in the dry skull where the alinasal 
cartilage has been macerated away. Besides the absence of the vomerine cartilages, we have, then, in the "Trochilidæ," a lax relation of the vomer to the alinasal wall (see figs. 2, 3, 8, 9, $v, i a l$ ), the two being connected by a fibrous ligament. But the bone is well shouldered, and above the broadish part the additional bones are seen, namely, the "septo-maxillaries" (figs. 2-4, $\sin x$ ), so that the morphological elements are all here except the pair of vomerine cartilages; yet the metamorphosis of the parts is arrested and the elements remain distinct. Besides the paired septo-maxillaries $(\operatorname{sm} x)$, there is an odd one, lying on the vomer, below the septum nasi, and in front of the small pair of centres (fig. 4, $j m x^{\prime}$ ). These three bones coexist in certain Agithognathre, as Gymnorhina, where they all coalesce with the vomer, and Homorus, where the median piece remains distinct. This azygous piece I often find when the vomer itself is azygous, as in Anser palustris, Psophia crepitans, Circus cyaneus, Haliastur indus, \&c.; it is related, morphologically, to the base of the cranio-facial notch, and is distinct from the centre which ossifies the postero-inferior part of the septum nasi. Thus the unspecialized submucous plates seen in the vomerine region of the Sturgeon reappear in their old profusion in these nobler types, but are specialized to the highest degree.

The next arch, the pterygo-palatine, has as much and as little of the Passerine type as the one described. The palatines themselves are of great length (figs. $8 \& 9, p a$ ), and are extremely slender, especially the distal part; they thicken gradually to the widest part, and then gently taper off to their posterior end. On the inside of the widest part ach bone sends forward a long interpalatine style (ipa); and on the outside a wart-like protuberance represents the transpalatine of the " Egithognathæ." This is only seen in the adult, and is a mere periosteal outgrowth (figs. $3 \& 4$, tpa).

In some low-type Passerines, such as Pipra and Pachyrhamplous, the transpalatine is not much larger; in the young Humming-bird the palatines are as much deficient here as those of the Hemipods. The ethmo-palatine lamina (figs. $9 \& 10$, epa) is very much stunted, the reverse of what obtains in the Swift and Goatsucker, where it is of extreme length; and in them the vomerine crura articulate and then coalesce with these laminæ, whereas they remain distinct in the "Trochilide." The short stoutish pterygoids $(p g)$ are scooped in front, where they rest upon the end of the palatines ; in the young (fig. 10, $p g, m s p g$ ) the mesopterygoid piece is nearly distinct from the body of the bone; it becomes quite separate, and then coalesces with the palatine. Both palatines and pterygoids are faceted with cartilage to glide upon the short, stout, flat-faced basipterygoids $(b p g)$. Each pterygoid is sharp-edged both above and below, and above the shallow cup for the pterygoid there is scarcely any epipterygoid process (epg). In this these birds are contrary to the "Agithognathæ." In the young (figs. $8 \& 9, m x$ ) the maxillaries are clearly traceable; the broad flat part is about equal in length to the long terminal spike, which is equal to that of the palatine; already, the posterior style (zygomatic process) has coalesced with the long jugal $(j)$. The dentary edge is quite overlapped by the premaxillary, opposite the end of which we see the characteristic ornithic process, the " maxillo-palatine."

These outgrowths from the maxillaries are of great interest to the morphologist; here, in the Humming-bird, they show relationship as by the most delicate test. In the young 
(figs. $8 \& 9, m x p$ ) they agree in general with those of young Coracomorphæ and Hemipods, but in particular with both young and adult of that family of birds which has most similarity to them in general bodily structure, namely Swifts ("Cypselidæ"). The process itself is at first a mere hook, moderately thick, rather long, curving at first inwards, and then directly backwards. This perfectly retrorsal rod runs directly along the inside of the palatine; in the Swift it clears itself of the palatine, and is altogether more flattened and sickle-shaped.

The maxillo-palatine of the "Trochilida" becomes more and more underlaid by the palatine (figs. $2 \& 3$ ), so that a lower view shows little of them, and the specimen has to be carefully studied in oblique aspects before its form and relations can be understood (fig. $4, p a, m x p$ ). Then it is seen that the little rod has become a flat thin plate, with a terminal hook, and with its lower edge entirely ankylosed to the palatine. This is similar to the condition of things found in Cranes and Plovers, and totally unlike any thing seen in the "Egithognathæ." As far as my memory serves me, I have never seen any ankylosis of these parts in the "Coracomorphæ," not even in such highly ossified faces as those of Phytotoma, Coccothraustes, Gymnorhina, or Artamus; the palatines, even in these, keep scrupulously apart from the overlying maxillo-palatines.

The huge nasal labyrinth is much more in conformity with its counterparts in the Passerinæ than the facial bars. The alæ nasi (aln), like those of the Hemipods, are large mussel-like valves, and have this special character, namely, that the widest part of the nostril is behind; the teleological meaning of this structure "lies at the door," like the other specializations of this type.

Unlike the generality of the small and delicate species of the "Coracomorphæ," such as Acanthorhynchus, Nectarophilus, Phylloscopus, Troglodytes, Chelidon, \&c., the nasal outworks and walls are extensively ossified. The posterior septal bone is present, and has a smaller ossicle in front of it (fig. 4, $s n$ ), and the anterior alar region (figs. 2-6, $a l n$ ) is ossified right and left in the recurrent lamina $(r c c)$ and in the free valves; in the latter there is a margin of cartilage left, and this has a selvedge of bone formed by a distinct centre on each side. This is the sickle-shape counterpart of the annular alinasal ossicle of certain Parrots (Melopsittacus undulatus \&c.). The large alinasal turbinals $(a t b)$ are ossified to a considerable extent, the inferior turbinals (itb) scarcely at all. The anterior nasal floor is but little developed; yet it sends inwards its inturned lamina ( $(\mathrm{ial})$, a broad unossified flap, to be tied to the vomer by a broad ligament $(\mathrm{ial}, \mathrm{v})$. The true olfactory region (ecto- and meso-ethmoids) is of great size, and is densely ossified: thoroughly Passerine, it has completely aborted the lacrymals, and appears on each side of the frontals above (figs. $5 \& 6$, eeth), whilst below it forms most extensive antorbital wings $(p p)$, the suborbilal part of which, reaching two thirds of the way towards the quadrate, has no separate ossification of the "os uncinatum."

The skull is depressed: grooved above symmetrically for the long hyoid cornua (3rd arch), it has its ethmo-presphenoidal plate (pe) solid, as in the Carp, and nonfenestrate. The orbito-sphenoidal lips are narrow, and the orbital plates of the frontal very little developed, so that the tilted floor of the cranium is largely membranous. The 
pier (quadrate) and proximal part of the mandible is much like that of the Swift. The symphysis is long, and the distal part a mere copy of the upper jaw.

The 2nd and 3rd postoral arches are merely outdrawn modifications of the normally ornithic hyoid bone, much less specialized than in the Woodpeckers. The true ceratohyals (fig. 7, chy) only extend for one fourth up the interior of the double horny sheath; but another fourth is filled, first with fibrous and then with fatty tissue. A short tract of each bar is ossified, and all but the small bilobate end of the middle, or basi-urohyal bar $(b h y, b b r)$. The proximal part of the 3rd postoral $\left(b r^{\prime}\right)$ is only about one fourth the length of the flat distal piece, which reaches, when the tongue is retracted, as far as to the premaxillary apices: both are fully ossified.

Any one who will repeat these observations will find that the "Trochilidx" have no right within the Passerine territory, and that they have at length diverged very widely from the most striking isomorphs within that range. The "Coccygomorphæ," if they be considered broadly, will be seen to be their truest relations; they are not, however, a normal branch, but should be looked upon as forming a very distinct secondary leader, arising close to the root of this widely ramifying group. It is well worthy of remark that that Caprimulgine outlier of the "Egithognathæ," the Swift, comes very much neare the Humming-bird than the "Nectariniida," birds so mimetic and isomorphic of these gorgeous "vertebrated insects."

On the Structure of the Face in Scythrops novæ-hollandiæ.

It would be difficult to find a more central form than Scythrops for the whole of the " Coccygomorphæ." It appears to be equally allied to the Hornbills (" Buceridæ "), the Toucans ("Rhamphastidæ"), the Plantain-eaters ("Musophagidæ"), and the true Cuckoos ("Cuculidæ"). This paper, however, is given, not so much for the elucidation of a difficult taxonomy, as for the purpose of exhibiting the more striking modifications of the face and nasal organs in highly specialized birds. Ankylosis is in this case carried to its uttermost limits as far as is consistent with the well-being of the type; yet the regions can easily be determined. Rudiments of basipterygoid processes (Plate XXIII. fig. 1, bpg) remain on each side of the subcarinate posterior part of the basifacial bar; the bar becomes rounded and synovial where it glides along the common palatine groove (fig. 2, $p e, p a$ ). In front of the hinge the bony septum nasi becomes lost in the delicate diploë that, sponge-like, fills the large upper jaw. Besides the huge premaxillaries, which have melted into the common mass of the upper face, there is a well-marked vomer (figs. $1 \& 2, v$ ), which appears as a thickish subcarinate plate of bone between the maxillo-palatine wedge and the approximated interpalatine lips. This lesser bony wedge thickens again above, and then thins out to articulate by fibrous tissue with a superoposterior ossicle. The vomer of Scythrops is an azygous bone, of the Chelonian type, such as is also seen in Raptorial Birds, and in Mammalia of the Cat tribe; but the hinder part has been detached, and has coalesced with the palatines ( $p t p a, v)$.

There is, however, another element of the trabecular arch in this bird, which makes it one of great interest to the morphologist; this is the os uncinatum. Notwithstanding the normally large size of the lacrymal (fig. 3, l), the ecto-ethmoid, or pars plana $(p p)$, 
is a great squarish plate of bone; as in Caprimulgus, the infero-external angle of this plate has its ossification stopped short, leaving that tract which primarily grew out of the trabeculæ to conjugate itself with its counterpart process on the palatine bar. This yoke-band is proximally broad and triangular (figs. $1 \& 3, o u$ ), and the apex of the triangle, which alone is ossified, grows into two long and slender lashes of cartilage, one of which runs directly across to its endoskeletal symmorph, tying itself to the very apex of the ethmo-palatine crest (fig. 3, epa, ou), whilst the other runs forwards and downwards, and is attached to the upper surface of the palatine, near its outer edge and opposite the fore margin of the maxillo-palatine floor (fig. 1, ou, mxp). The strong palatine arch has, notwithstanding its intense specialization, attained the very form which the foremost (trabecular) arch assumes as soon as it can be seen in a vertebrate ambryo as clouded bands of granular bioplasm. Here we have symmetrical sigmoid oands, which behind (at their apex) are strongly hooked upwards and inwards; these bands approximate, coalesce, and then diverge to their free flat anterior ends. Whilst andergoing this junction the trabeculæ form not only a commissure but a crest; here, in the palatine arch of Scythrops (figs. 1-3, pa, epa, pg, mspg), each bar grows upwards at the commissure, which forms a semicylindrical trough above (fig. 2), on each side of which the ethmo-palatine processes (trabeculo-palatine conjugational outgrowths) project.

Each pterygoid $(p g)$ expands in a very ichthyic manner on the fore edge of the quadrate, the expansion being the posterior margin of the subterminal part of the bar; the real apex is the epipterygoid hook $(e p g)$, which is as well developed here as in the Finches. Each pterygoid is a strong bone, sharply keeled both above and below; leafy above and hooked below, where it articulates with the palatine. It has evidently yielded a mesopterygoid element ( $\mathrm{mspg}$ ) to the upper cartilage of the palatine behind.

The postpalatine region is vertical, the prepalatine broadly horizontal; the middle part is mixed. The upper edges have united by ankylosis, not, however, without a key-stone, a detached postvomerine piece, and perhaps also a medio-palatine (figs. $1 \& 2, v, p a)$.

The deep thick-edged interpalatine lips, where they embrace the exposed vomerine plate, nearly meet (fig. 1, ipa), so that altogether the lower or hard palate is of great extent and complexity. By far the greater part of the hard palate is due to the larger growth of the median and lateral palatine portions of the overgrown premaxillaries $(p p x)$; but there is no little of the maxillary element besides. The proximal or lateral portion of the maxillo-palatine plates (figs. $2 \& 3, m x p$ ) is spongy and of great width; it rises (fig. 3) up in front of the ethmo-palatine (fig. 3, epa); but the heart-shaped median portion, which belongs to both sides, fills in half the space between the median palatine process of the premaxillary and the gap formed by the diverging palatines. My figure (fig. 1) does not show more than the inferior surface of this common median maxillo-palatine mass; but above, in front of the rertical vomer, it swells out into a very elegant bulb of spongy bone, which is exactly heart-shaped, the base looking upwards. The ankylosed "jugal" bar $(j)$ is strong, and greatly inhooked behind. The small ossified alæ nasi with their bony rudiment of a turbinal (fig. 3, aln, atb), form a nostril that looks downwards and backwards. The whole labyrinth is buddled into a small 
space between the nostril and antorbital, and the short inferior turbinal is ossified. The ecto-ethmoid (fig. $3, p p$ ) is entirely excluded from the frontal region.

On the Structure of the Skull in Megalæma asiatica.

Having described a good representative Cuculine face, I take as my next instance that of a bird which has a doubtful and mixed morphology. The physiognomy of the living bird corresponds with this; for the most trained eye, seeing it for the first time, is arrested by a sort of play and interchange of features, now looking like a relative of the Cuckoo, and anon seeming to belong to the Southern Shrikes or Crows (e.g. Vanga, Coronica, Gymnorhina).

Seen from below (Plate XXIII. fig. 4), the imperfectly "desmognathous" and semipasserine characters are seen at one view. The bony structures have the same Owl.like spongy character as is general in the Cuculine birds; in the "Coracomorphæ" they are more fibrous and stronger; they are more cleanly built.

In Megalcma the basipterygoids are quite aborted, and the basifacial beam is rounded to its end, the parasphenoidal rostrum ending below the hinge as a blunt spur. In front of the hinge there is a solid postseptal bone, which ossifies that part of the trabecular bar; for the rest, the septum nasi is aborted to a great degree, yet the recurrent alinasal folds send backward a style of bone which reaches almost to the vomerine forks. The nasal labyrinth has its scrolls stunted; those of the "alæ" are partly ossified, and the alinasal wall has become thick bone externally $(a l n)$; in front this bar divides the external space into an anterior true and a posterior false narial opening, as in many Cuculines.

The spongy premaxillaries are remarkable in having their thick, hollow, rod-like palatine processes free posteriorly (fig. $4, p p x$ ). The dentary termination is equally thick, but its lower edge is sharp and dentate.

The os uncinatum is not distinct from the pars plana (figs. $4 \& 5, o u, p p$ ), but it has retained its primary embryonic shape as a somewhat hooked triangular flap. The vomerine series of trabecular splints is extremely interesting. There is no evidence of a cartilaginous origin for the evidently double vomer $(v)$; but its explanation must be sought for in a series of forms outside the Cuculine boundary, as well as near the border, namely, in the Humming-bird. As in Gymnorhina, Homorus, and Trochilus there are five vomerine bones, two vomerine moieties, forming a most elegant $\mathrm{Y}$-shaped bone, a pair of septo-maxillaries, and a median piece (fig. $4, v, \operatorname{sm} x, \operatorname{sm} x^{\prime}$ ). When the septomaxillaries are well developed, as in the "Ophidia," they stretch themselves beyond the vomers, fore and aft, as is well seen in the Cobra (Naja tripudians); but when they are feebly developed, a bony rudiment may appear in any part of the tract occupied by them in their larger growth.

Thus in the Sparrow (Plate XXI. fig. 4, smx) they appear outside the broad shoulder of the vomer; in the Humming-bird in front of the broadest part; and here, in Megalcema, behind, answering to that terminal spike of the bone in the Cobra which articulates with the ethmo-palatine crest. I am satisfied that this is the true interpretation of the posterior pair of vomerine bones in Megalama; for the bone does not form a palatine com- 
missure, and the medio-palatine, which occurs there, is azygous. The median septomaxillary turns up again in the Woodpecker; it has been already deseribed in the Humming-bird (Plate XXII. figs. $3 \& 4, s m x^{\prime}$ ) ; it exists free in the Coracomorphous genus Homorus, and ankylosed to the vomer in Gymnorhina. For a vomer like the one figured here (fig. 4, $v$ ) we must look to some Celebesian Passerines. I have it in Nectarophilus Grayi and in Anthreptes malacensis; especially characteristic is that of the former* .

But the vomer in these Passerines is confluent by its forks with the inturned alinasal wall; in Megalama the arms of the $Y$ form a neat joint, apparently without a cavity (Plate XXIII. fig. $4, v, m x p$ ), with the corresponding maxillo-palatine plates. The nearest relation of this type known to me at present is the Roller (Coracias garrula): this is one of Cuvier's " Passerinæ;" but it is far less passerine than Megalcema, and has a chelonian azygous vomer. The narrowish, parallel, neat palatines are very much like those of the Roller, but they are narrower, have a less distinct inner keel, and have distinct interpalatine processes $(i p a)$; the rudimentary transpalatine angle $(t p a)$ is nearly equal in the two kinds. The large mesopterygoid (fig. $5, \mathrm{mspg}$ ) is semidistinct, and has not united with the palatines in this specimen. In Coracias these parts are quite passerine, the mesopterygoid having united with the palatine on one side, the left, whilst on the other all these are fused together. In Coracias the epipterygoid process is abortively developed; in Megalcma (fig. 4, epg) it is an elegant rounded lobe. In Coracias the maxillo-palatines are large, and have a complete ankylosis with each other; in Megalcema (fig. 4, mxp) they are smaller and do not meet, being kept apart by the "median septo-maxillary" $\left(\sin x^{\prime}\right)$.

In Coracias the lacrymal has its largest development and the ecto-ethmoid the least; in Megalama these things are reversed, and the lacrymal (fig. $5, l$ ) is a mere point, whilst the ecto-ethmoids (eeth, $p p$ ) are like those of the Passerines and Hemipods, being largely exposed in the frontal region. In the structure of the nostrils the two types agree; but conformably with its more intensely cuculine character, the Roller has a very massive, spongy, osseous nasal septum; it also has very large but non-functional basipterygoids.

The characteristic modifications of Coracias are exaggerated in Eurystomus, save that its basipterygoids are aborted. In no Owls that I have seen does the bone become so frail a sponge as in the enormous lacrymals of that type; the ecto-ethmoids are in it very minute flaps, the outer part of which is not ossified, as in Caprimulgus. Eurystomus is a Roller, making no inconsiderable approaches to the Owl-like nocturnal Cuculines next to be noticed.

The first of these is the Guacharo, or "Oil-bird" (Steatornis caripensis, Humb. ; Podargus, Cuv., Temm.).

The high arch both of beak and skull makes this bird's head most completely isomorphic of that of the $\mathrm{Owl}$; its basipterygoids are well developed (of enormous breadth, the articular facet being oblong rather than oval), thus agreeing with the Owl and Fern-

* The figures and descriptions of these forms, and of many others referred to in this paper, will soon appear in the 'Zoological Transactions.'

SECOND SERIES.-ZOOLOGY, VOL. I. 
Owl at once, and departing from Podargus; Stealornis also agrees with Caprimulgus in having the proximal part of the large flat antorbital (ecto-ethmoid) ossified. I mention these things here to distinguish this type from the next to be described; a full account of it must be reserved for another time and place.

\section{On the Structure of the Face in the Giant Goatsucker (Podargus).}

Having been led up to Podargus by a series of marginal and of central Cuculine forms, I am anxious in this paper to give the most intensely modified form of face that has as yet come under my notice. A face and skull are present here which, like that of the equally specialized skull of the Crocodile, give us a prolepsis of that of the Mammal, with its hard palate, the last degree of desmognathism having been attained.

This apparently ancient type, perhaps an early tertiary or even secondary waif, is also, like the Oil-bird, an isomorph of the Owl, but not to the same degree. The huge upper face, mimetic of the succulent leaf of an Aloe or a Mesembryanthemum, is mainly composed of the premaxillaries and maxillaries (Plate XXIII. fig. 6). The figures already given of the small and somewhat Passerine Fern-Owl (Plate XXI. figs. 8-11 and Plate XXII. fig. 1) will help the student to understand the development of this thick, arched, scooped, and although apparently solid, yet in reality spongy face. From the terminal hook of the neb to the frontal region above, and to the truncated palatines below, there is no trace of a suture. To make the division below the fore face on the one hand, and the hind face and skull on the other, more complete, the jugal process of the maxillary is absorbed, and the jugo-quadrato-jugal bar articulates with the maxillary inside its dentary angle. Here, then, the only movement possible is at the cranio-facial hinge; for the pterygoids overlap and are tightly strapped to the palatines. The great main hinge is behind, namely, that of the quadrate upon the auditory wall (fig. 7, $q$ ). The motion here is almost as limited as in the claw-hinge of a Lobster.

A rudiment of the basipterygoid is seen as a ridge, somewhat pointed in its middle, which runs from the optic foramen below, and is soon indistinct. Between these ridges the basifacial bar is subcarinate, and then flattens out, running into short bony wings, which are the proximal parts of the ecto-ethmoids; these are squarish flat cartilages (Plate XXIII. fig. 7, $p p$ ). The septum nasi (fig. 7) is flat, bony, and notched behind, below the groove for the nasal nerve; the hinge between the septum and the mesoethmoid (fig. 7, pe) is perfect. The fore part of the median ethmoid is slightly keeled between the antorbitals; its line is forwards and upwards equally. The alæ nasi and all the turbinals are unossified, and are extremely small and feeble; for the descending crus of each nasal, and the face-plate of the maxillaries, straighten the nasal cavities into two widish tubes. The posterior trabecular splint, the parasphenoid, does not project in front, and is very short; the great anterior splints (premaxillaries) have few rivals in relative size. With the nasal labyrinth so aborted the vomerine bones were likely to be feeble. A flat band of fibrous tissue runs from a very soft bar of bone in front $(v)$ to the ethmo-palatine hooks behind (fig. 9, epa). Below, in front, we see this spongy wedge; it is higher at its smooth lower face than the great maxillo-palatine plate $(m x p)$ to which it is ankylosed. Above, in the end of the membranous vomerine band, there is a small 
ossicle, which lies between the ethmo-palatine hooks (fig. 9, $\left.v^{a}, e p a\right)$; this is a minute posterior vomer, this element being double, as in Scythrops and other "Cuculinæ."

Caprimulgus is very passerine in having a huge double (symmetrical) vomer (Plate XXII. fig. 1, $v$ ); but Steatornis comes much nearer Podargus, and has an azygous vomer, of a clubbed shape in front, articulating with the palatine commissure. But the flat anterior foot of the Chelonian vomer is again, as in Podargus, represented by a small bony wedge in the cleft behind the maxillo-palatine synostosis.

The elegant leafy palatine arch is as fraught with interest as any other part of this bird. The long prepalatine bar is aborted (compare Plate XXI. fig. 8, prpa, with Plate XXIII. fig. 6, prpa); the broad truncated ends of these, the shortest of ornithic palatines, are joined to the great fore jaw by a half-ankylosed dentate suture. For short distance they are distinct, but they soon converge; these interpalatine plates are ankylosed together, and form a bony raphe below to this superaddition to the bird's hard palate. This line of union is half the length of the palatines; a rounded notch separates the extreme ends of the bars. The transpalatine process is triangular, with a rounded point; it is not one third the relative size of this part in Caprimulgus; in Steatornis it is entirely gone, as in many Cuculines. In that intermediate Goatsucker the interpalatine processes are rounded lobes, that grow near to each other in a horizontal manner, but do not meet; whilst in Caprimulgus (Plate XXI. fig. 8, ipa) the interpalatine ridges run parallel a long way, a short distance apart, and end in a delicate spur. In Steatornis the ethmo-palatal commissure shows no medio-palatal keystone as in Caprimulgus (Plate XXI. fig. 9, mpa); but in Podargus, although this tract is very short, only half the extent of the lower hard floor, yet here, again, we have the two azygous medio-palatines, the undoubted symmorphs of those $I$ have described in the Fern-Owl (Plate XXI. fig. 9, mpa, and Plate XXIII. fig. 8, mpa). In Steatornis the palatine commissure is longer than in either the Giant or the Common Goatsucker, more like that of Scythrops (Plate XXIII. fig. 1, ipa); the posterior notch is similarly small.

In all these thin types the apex of the palatine arch, or epipterygoid, is aborted, and in Podargus and Caprimulgus this bone is very spongy (Plate XXIII. figs. $6 \& 7, p g$, and Plate XXI. fig. 8, pg); in Steatornis it is less spongy and more crested. In this latter bird the facet for the basipterygoid has an overlapping process, by which it lies over as well as against the basal facet; in Caprimulgus there is a slight rudiment of this structure; in Podargus there is no joint at this part. All these three types agree in being embryonic, as regards the mesopterygoid. This spur does not segment off in either; in the old Fern-Owl it has become aborted; the young agrees with Steatornis and Podargus (Plate XXI. fig. 11, and Plate XXIII. fig. 7, pg); it lies in a depression and is strongly bound to the supero-median surface of the palatine. I find no defined os uncinatum in either the Fern-Owl or Podargus; but in Steatornis it is as well developed as in Scythrops (Plate XXIII. fig. 1, ou), and has two cartilaginous tapes that tie it in front and behind.

The lacrymal is large in the Fern-Owl (Plate XXI. fig. 8, $l$ ); in Podargus it seems to be absent; but a small ossicle may have coalesced with the supero-external angle of the nasals, in front of the narrow frontals, as is the case with a larger piece in Steatornis. 
The face of Steatornis is much like that of the Eared Owl (Asio otus), but the alæ nasi are much more ossified; they are quite soft in the other two, and only the fore edge is left cartilaginous; its septum nasi is also bony.

This agreement and disagreement, alternately, of these three Goatsuckers suggests the probability that they each represent what were once large " subfamilies;" but their characters, by their intense inosculation, show that they belong to one highly natural group.

The stapes of Podargus presents a very curious and instructive example of this hyootic structure. The otic portion, or basal plug (figs. $10 \& 11, s t$ ), and the medio-stapedial bar (mst) are quite normal. The "suprastapedial" (sst) is large and unossified, and so also is the infrastapedial (ifst), which ends below, continuously, in a spatulate recurved stylo-hyal. The thing, however, to be noticed is the huge roughly spoon-shaped extrastapedial (est), all bony, convex outside, concavo-carinate within, and pneumatic; the upper margin is evenly sinuous, the lower and the end sublobate; there is a fenestra between it and the falcate suprastapedial (fig. 11). A ligament is seen growing from the top of the extrastapedial spoon; and another larger ligament ties the suprastapedial to the prootic wall. The cartilage of the supra- and infrastapedial is continuous; the line of the original arch or bar is from the mediostapedial to the infrastapedial, whilst the suprastapedial becomes a second head; the extrastapedial is a conjugational outgrowth. The bifurcation of the rod above produces processes which are the isomorphs of the capitular and tubercular processes of a true rib; the suprastapedial resembles a tuberculum, and the mediostapedial a capitulum; the shaft, as wa saw in the Martin, chondrifies in patches, the backwardly bent stylo-hyal reuniting with the upper piece by a later chondrification of the infrastapedial tract.

On the Structure of the Face in some other "Coccygomorphæ."

In the Hornbills, the secondary growths of the trabecular and palatine arches, more especially the former, acquire the uttermost degree of prognathic development consistent with the mechanism of a bird's skeleton as such. The result, taking in the correlated modifications throughout the rest of the skeleton of these birds, is a form which makes the conception of the living Pterodactyle an easy effort of the fancy. Pneumatic overgrowths, of such a size as we see in the larger species, intensify the grotesqueness of the creature; for the aneurismal bursting of the bony walls by the imprisoned breath has resulted in their huge air-chambers, walled in merely by the horny epiderm and its filmy quick. For a figure of the palate of Buceros bicornis the reader is referred to Professor Huxley's paper (op. cit. p. 446, fig. 28). Here the bony bar between the apertures marked $a$ is the foot of the Chelonian vomer, separated from its posterior portion by a membranous space, and ankylosed to its surroundings, namely, the maxillo-palatines and the coalesced interpalatines, behind; for these larger species have a palatinal hard palate. The styloid posterior part is ankylosed with the palatines at their upper or true commissure. I see a similar structure in B. ruficollis, Temm.; but the interpalatines are imperfect, and the form of the vomerine foot is not so easily traceable. In this species the notch which forms the cranio-facial hinge is reconverted into a fenestra by a tuberous growth of bone, 
a median septo-maxillary, which runs from the parasphenoidal beak to the bony septum nasi, above the posterior vomer. The os uncinatum is not distinct in these Hornbills, but the ecto-ethmoid terminates in a large pedate process which binds upon the zygoma; their lacrymal is aborted, and the large lateral ethmoid comes to the outside and top of the face, as in Megalama and the Passerinæ. With the complete ankylosis of the palatines at their commissure, nothing can be learned from the adult as to the existence of a medio-palatine keystone.

In the most exquisite of all vertebrate skulls, that of the Toucan (Ramphastos toco), the structure largely agrees with the "Buceridæ." The ecto-ethmoid projects as in them and the Passerinæ, and the os uncinatum is represented by the pedate angle of that bony plate. I see a small lozenge-shaped subcarinate vomer below the level of, but acting as a secondary keystone to, the palatine commissure; this, however, is only the posterior vomer. The anterior piece is a broad bifid ragged wedge of bone, with its narrow angular end dovetailed in between the palatines, immediately above the small spiny semidistinct interpalatines; its position is transversely vertical, and its size ten times that of the hinder piece. The notch is complete that forms the wide hinge between this marvellous face and skull; it is $1 \frac{1}{2}$ inch across, and the beak of the parasphenoid is but little behind a descending plate of bone, the sharply bifid middle portion of which is the posterior. angle of the nasal septum. The anterior vomer reaches upwards to these three bony spikes by its ragged split upper end. The nostrils are nearly half an inch apart on the upper surface, close in front of the hinge, and overshadowed by the rounded posterior margin of the elevated beak. The thoroughly ossified alæ nasi enclose a transversely oval nostril; the other parts of the nasal labyrinth are all ossified, and the inferior turbinals are exquisite little scrolls of scabrous bone, almost pisiform, and vertically placed, the end of the scroll being seen from below instead of in front as in other birds. Between the splintery prepalatines and the maxillary synostosis there is a rather large oval space; behind, the palatines are fused together.

The transpalatine region, with its retral spike, is something between what we see in Megalama (Plate XXIII. fig. 4) and in Dacelo (Huxley, op. cit. p. 447, fig. 29, Pl). The basipterygoids are small rudiments; the pterygoids are spongy, and have a small epipterygoid lobe. This short initial description may help the student to decipher the morphology of this culmination of the "Coccygomorphx." I have just referred to Professor Huxley's good woodcut of the palate of Dacelo ; in my specimens of the "Alcedinæe," namely, Alcedo ispida, Upupa epops, Todus viridis, I see no vomer. These skulls are thoroughly "Desmognathous," and are especially interesting as to their palatines, in which the transpalatine sends backwards a spike, equal, in Alcedo, to the prepalatine style in front; in the young Hoopoe the transpalatine is obliquely set on to the palatine as a distinct bone.

In the "Musophagidee" the os uncinatum attains its fullest development as an anterior transverse bone (see Dr. Reinhardt's paper, already quoted). In a species of Corythaix. (? buffoni) there are two medio-palatines and a posterior vomer; these lie behind the short sutural commissure, in fibrous tissue; for, posteriorly, the rounded palatines are wide apart, exposing the parasphenoid. 
The foremost medio-palatine is a minute style, having the equally minute styliform vomer beneath it; the second medio-palatine is a mere grain of bone *.

The nasal labyrinth is well developed in these birds, and is thoroughly ossified; so that the bony skull of no other bird is so useful to the student who would master this elegant sense-organ.

On the Structure of the Skull in Birds of Prey (" Aetomorphæ," Huxley).

Both for this and for the Goose tribe I have sought to extend the lines that bound in their "lot," confident that in the Southern World we have extant, and, to a much greater degree, in the buried Tertiary world there are extinct, many a type that cannot and could not wear the ordinary ornithological harness. The characters of an Eagle, a Falcon, or an Owl may easily be set down; but when the scientific formalist comes athwart a bird in which all these are shaken up together, like the lots in the helmet of Agamemnon, then every thing breaks down, and his wire-drawn distinctions lose their value.

Yet these distinctions are not the less valuable, being applicable to the newest and most specialized forms; but they melt away in certain types, just as the professional distinctions of civilized life are seen to melt away when we contemplate the life and polity of savage races.

I make these remarks in defence of the position in which it is here sought to place a bird, the Cariama, the relationships of which seem to me to be self-evident, and which has been looked at by most ornithologists through the coloured and refracting glasses of their own arbitrary systems.

Having no misgivings as to the essentially Raptorial nature of the Cariarna (Dicholophus), I do the more boldly place it for comparison side by side with the two most intensely specialized types in the whole group, viz. the Falcon and the Owl. Such a collocation, however painful to the eyes of full-grown systematists, will, if its naturalness be proved, be of real value to the tentative worker, serving at least as a hint that the strength of Nature will burst the new ropes we seek to bind her with, those bonds being, indeed, as weak " as the tow when it smelleth the fire."

On the Structure of the Skull and Face in Dicholophus cristatus.

The form of the whole head in this bird is Vulturine (Plate XXIV. fig. 2), as may bo seen at once if it be compared with that of Gyps fulvus (fig. 1) †.

* It is not always possible to be absolutely certain as to whether any given grain of bone belongs to the hinder part of the vomerine region or to the palatine commissure.

+ How the eyes of naturalists have been holden against seeing the truth here I cannot understand; the legs of the bird, so thin and long, have robbed it of its aquiline glory. A few years since, showing two of these birds in the gardens of the Zoological Society to my brother, a man of like tastes with myself, he at once recognized the Cariama as a kiod of Hawk, whilst it crouched upon the perch. Another individual was standing in the enclosure in front of the aviary: "What bird is that ?" I inmediately asked. "I cannot say," was the answer.

Capt. Burton ('Exploration of the Highlands of the Brazil,' London, 1869, vol. i. p. 57) compares this bird with the Secretary (Gypogeranus), and says that it has the same serpent-eating tastes (see also vol. ii. p. 18).

The keeper of the aviaries where the Cariamas are kept informed me that they eat mice and sparrows, beating them about before they kill them. On July 31 st, 1872 , I watched both $D$. cristatus and $D$. burmeisteri dust them- 
The first and most notable difference between the skull of the Cariama and that of Gyps fulvus is that it is generally feebler (Plate XXIV. figs. $1 \& 2:$ fig. 1, Gyps; fig. 2, Dicholophus), and its ossification is arrested; but it has the elongated vulturine face; whilst Gypogeranus comes close to the Harriers, Kites, and Buzzards.

The first and leading characteristic of the skull in this type is its palate, which corresponds to that of a young Falcon (Plate XXIV. figs. $3 \& 4$ ), and gives me that modification of the Desmognathous skull which I have termed (supra, p. 112) " imperfectly direct," the maxillo-palatine plates $(m x p)$ being united by harmony-suture and not by coalescence.

How this skull has been taken for one of the "Schizognathous" type, and put with that of Cranes and Bustards, I cannot understand. In respect of its feebly ossified nasal labyrinth, this form approaches and agrees with other South-American types, namely the "Cathartidæ;" and the skull of Sarcoramphus has greatly assisted me in working this kind out; but there is no kind of Raptorial skull that it is not, more or less, in harmony with, in one point or another; and the whole group of the Aetomorphæ may. in some long past epoch have lain in the loins of a bird but little different from the Cariama.

There are three main varieties in the general bony characters of the Raptores: in the Cariama the skeleton has a fibrous lightness and delicacy, in the Owls a soft spongy condition for the most part, the long bones being dense as to their walls; but these are of extreme tenuity. In the Falcons the bones, everywhere, are almost like ivory in their density, reminding one of those of Serpents.

The skeleton of the Cariama has very little in common with that of the Crane tribe; it is as delicate, relatively, as that of that lonely waif of a subfamily of the "Gruinæ," the Sun-Bittern (Eurypyga helias), and still more like that of another subextinct type of ancient and generalized Cranes, namely the Kagu (Rhinochetus). But the Crane with which one would naturally compare it is the Trumpeter (Psophia); nothing, however, can be more fatal to the view of its being a Gruine bird than such a comparison: I would rather make room for it amongst the Gallinaceous birds than see it so misplaced. In the genealogical life-tree of the families of Birds, some grow near to each other, and have, as it were, their branches forming an acute angle with their leader, as in the Lombardy poplar; whilst others, as in the black poplar, grow out at all angles, most of which are wide and divergent.

If we take the "Coracomorphæ," they do so cling to each other, diverging very gently; but the "Aetomorphæ" delight in wide and wild divergence; and although manifestly " of one blood," they yet have acquired the greatest variety in their specializations ; but the Falcon is " brother to the Owl."

Notwithstanding the enfeebled length of the beak of the Cariama, the bones are thoroughly fused together. The broad basitemporals (fig. $3, b t$ ) end in front, as in the

selves by rolling exactly like the Common Fowl : this is in harmony with the fact that they impinge very closely on the gallinaceous circle. They are Raptores with a very gallinaceous aspect; whilst the vulterine Guinea-hen and the Brush-Turkey are Fowls with a very vulturine aspect. 
Owl (fig. 5), in two pouting lips; they underlie the common Eustachian opening (eu); outside and in front of this emargination the basipterygoids $(b p g)$ are seen projecting from those wings of the parasphenoid that form the "anterior tympanic recess." The narrowed part of the parasphenoid (pas) is relatively slender, and the pterygo-palatine bones undergird it for most of its extent. The great anterior palatine interspace is large, but it is lessened in the dry skull by an ossification which has affected the retral part of the trabeculæ and alæ nasi (fig. 3, aln). A similar bony bridge is formed in Sarcoramphus papa by the maxillo-palatines where they join the nasal septum.

Most of the nasal capsule, as in pluvialine and gallinaceous birds, is unossified. The vomer (fig. $3, v$ ) is of a type rare in birds; it is thoroughly Chelonian, more so than in any other bird save the Falcon (fig. 4,v), although some approach is made to this in the Sacred Ibis and the Tree-Duck (Dendrocygna).

As in the other Raptores, it is truly azygous, so also it is in the Gallinacex; but in the Cranes and all pluvialine birds it is composed of long lathy pieces, that converge and ankylose, only keeping apart behind.

In the Chelonia the azygous knife-shaped vomer spreads out behind and above to articulate with the orbital plates of the palatines, whilst in front it descends and helps the maxillaries to form an anterior hard palate. Just so does this bone behave in the Falcon and Cariama. In the Green Turtle (Chelone midas), however, the palatines have a small palatine lamina joining this fore foot of the vomer; this part is arrested in the Cariama and the Falcon (figs. $3 \& 4, p r p a^{\prime}$ ). In a side view the vomer of the Cariama (fig. $3^{a}, v$ ) is seen to be very high in the middle, low and flat in front, and gradually to lessen behind; the middle part is deficient of bone for a large space. This vomerine fenestra is repeated in the large Falcons (Plate XXV. fig. 12). The articulation of the vomer with the ascending or orbital plates of the palatines is through the medium of the keystone-piece of that arch, the medio-palatine (mpa). This bone is of great interest; hitherto I have only found it in Birds, and amongst them most developed in Woodpeckers (Trans. Linn. Soc. ser. 2, Plate II. p. 9). But it has just been shown to exist very commonly in Cuculine types.

There is no abrupt line of demarkation between this ossicle and the paired mesopterygoids; and all the gradations are seen in the Raptores, where these intercalary pieces are very variously developed. In the Cariama it is a roughish wedge of bone, rounded behind, pointed in front, and wedged in between the right and left ethmopalatines laterally; vertically is jammed in between the parasphenoid and vomer. There is one ossicle here in the young of Falco tinnunculus (fig. 4, mspg); but this is the apex of a right mesopterygoid, the left being suppressed. In Sarcoramphus (fig. 19) it is more truly azygous; in Neophron (Plate XXV. figs. 14 \& 15) it is a notable right mesopterygoid; but in that bird the mesopterygoid appears at both ends of its region (fig. 16), a little grain of bone occurring at the junction of the pterygoid on the same side.

In Helotarsus ecaudatus there is one small bone (a right mesopterygoid) in front (Plate XXV. fig. 9, mspg); but certain Owls (Strix stridula, Plate XXV. fig. 20, and 
Ketupa ceylonensis, Plate XXV. fig. 11) come the nearest to Dicholophus in respect of this bone and its relation to the vomer; but in these birds the vomer has no fore foot*.

The prepalatine bars ( $p r p a)$ are long and slender; the transpalatine is rounded off (tpa), and passes into a short postpalatine ( $p t p a)$, on the inner margin of which the submesial muscular ridge ends; the whole form and manner of these parts is Falconine, but drawn out. The upper part, or ethmo-palatine (epa), meets its fellow process for some extent in the middle, the fore end diverging for the medio-palatine keystone (mpa), and the hinder for articulation with the diverging pterygoids $(p g)$. Threads of bone represent the interpalatine ( $i p a$ ), which, if developed, would have given a desmognathous palate, bound together in the same manner, and composed of the same parts, as that of the Green Turtle, which has the anterior vomerine foot inwedged between rudimentary palatine plates of the maxillaries and palatines. This Reptile stands halfway between the Lizard, with its highly schizognathous face, and the Crocodile, in which desmognathism is carried to its uttermost, as in the Mammalian genus Myrmecophaga. Half the charm of this research would vanish if we could possibly forget that the bird groups are luxuriant outgrowths of the reptilian understock, and that their fiery nature once lay hid in the stone-cold Reptile.

Some of the Raptorial characters of the Cariama are exaggerated. The shortness of the pterygoids $(p g)$ is greater than in the Owl and Falcon; they answer, however, exactly in character to those of the latter, having no articular junction with the basipterygoid processes $(b p g)$, these being arrested. Their epipterygoid process (epg) is a hooked flange. The splints of the face are confluent, the marginal line being continuous from the neb to the quadrate hinge; the hinder jugal bar is slender. About two fifths of the premaxillary mass is continuous in the fore palate; the palatine processes of the premaxillaries are long, slender, and lie outside the prepalatine laths. At the middle these large bones are again united by a commissure, namely, the alinasal bridge (aln).

But the most remarkable part of the face is the maxillo-palatine floor, which is relatively larger than that of almost any bird; the processes forming this hard palate are flat ear-shaped lobes, which unite at the mid line by harmony. They are pointed behind to let in the foot of the vomer, and broad and notched in front, behind the large anterior palatine space. These plates have the thin fibrous character of the main part of the skeleton, instead of being dense as in the Falcons, or spongy as in the Owls. The skulls of those types when young (figs. 4 \& 5) are exactly correspondent in their essential morphology to that of the Cariama, being of the "imperfectly direct" desmognathous type.

The general form of the skull seen from above, with its alate lacrymals, is evidently an enfeeblement of the vulturine type (fig. 2) as compared with that of Gyps fulvus (fig. 1); and what arrest and feebleness there is belongs not to the Crane, with its dense heavy skull and square-browed lacrymals, but is something intermediate between that

* I have the more carefully gone over these details because of the instructive fact that the structure of the Cariama is best explained by that of the various Raptorial subfamilies, and is not illustrated by members of the family to which it has been supposed to belong. My notes on the soft parts of this bird, and the observations and comparisons I have made of the rest of its skeleton, all tell the same tale.

SECOND SERIES.-ZOOLOGY, VOL. I. 
of the Fowl and the common Vulture. In the Crane, a truly pluvialine bird, the maxillopalatines project but little mesiad of the prepalatine bar, the huge almost struthious double vomer being wholly displayed in the upturned palate.

Structurally, then, the Cariama is seen to have the remotest relation to the Pluvialine type; and if the details just given be weighed and measured, they will show that its Raptorial characters vastly preponderate; that it is evidently a branch of the same stock as the true Gallinacex, especially the Megapods and Curassows, and that it does not belong to any extant type of Raptorial bird; but as the Palamedea is a Chenomorph, so is the Cariama an Aetomorph, not holding out the flag of any one party of that commonwealth, but being, as it were, a representative of the old fathers of the race, whose sons have acquired such sharp characters of dissimilarity. It contains in itself not merely the attributes of a single subfamily, as Hawk, Falcon, Owl, Vulture, but "all these in their pregnant causes mixed."

There is a bone on each side in the face of the Cariama which is not seen well in the palatine view; this is the os uncinatum (Plate XXIV. fig. $2 a, o u$ ); it is well seen in the. side view.

As I have shown in the former part of this paper, this is common in the Cuculines ; in Dicholophus it is sinhilar to but larger than its counterpart in the Gulls (Plate XXVII. fig. 11, ou). It has a like development in the Alabatross, and is abortively seen in Uria troile and Alca torda. I find it in no other Raptorial bird, nor in any of the Grallæ that lie on the same morphological level as the Cariama, and although not belonging to its group have yet some affinity with it.

Here the bone is a notable style perched upon the zygoma, and underpropping the lacrymal $(l)$; it is, however, connected with the feebly developed pars plana $(p p)$, the free tongue-shaped part of which is unossified as in the pluvialine types.

This is the ornithic representative of the cartilaginous bar which yokes the trabecula to the palatine in the Frog, and therefore of great interest morphologically.

On the Structure of the Skull and Face in the Falcon (Falco tinnunculus).

Having treasured up from time to time every obtainable stage of young birds, I am able to compare the adult Cariama's skull with the immature skull (that of fledglings) of the Falcon, the Hawk, and the Owl, the proper morphological counterparts of the skull of such a root-form as the one just described *.

I trust to the trained eye of the ornithologist to see at once the essential agreement of this Falconine palate (fig. 4) with that of the Cariama (fig. 3). Nature, anti-Procrustean in all her works, has developed one skull into a form which is feline in its shortness, massiveness, and strength, whilst the other is outdrawn, and, as it were, of a vulpine shape; yet the "habit" of both types is manifestly one. The difference depicted is not the full measure of what would have been seen if an adult Kestrel had been selected for comparison.

* The same method with regard to the relation of the Plovers to the Gulls has appeared to be fruitful to my accomplished fellow workers, Professors Huxley and Newton; and their coinciding judgment has been to me in no little degree determinative of renewed labour in this field. 
The transverse basitemporals (fig. 4, $b t$ ) have joined their wings beneath the common Eustachian opening (eu). Above this point the parasphenoid (pus) is seen with small basipterygoid knobs (bpg), and above these and the basitemporals expands on each side into a large trumpet of bone, whose mouth opens into the labyrinthic drum-cavity. These trumpets form the "anterior tympanic recesses," and are lipped by one or more additional (tympanic) ossifications.

The fore part of the parasphenoid has the shape of a planter's dibble, and ends, bluntpointed, above the palatine commissure, carrying the hinge mesethmoid on its grooved upper face. The premaxillaries form a triangle whose sides are but little longer than their (ideal) base from side to side, and after forming themselves separately on the spatulate prenasal cartilage, combine at the mid line, not only above but also below, aborting and taking the place of their model, growing even there much more solid than their displaced prototype.

This is the most Chelonian of all the birds' skulls examined by me; and knowing full well that the bird's skull, after it has fused its trabecule and acquired a cartilaginous consistency, takes on immediately the most unmistakable Rhynchosaurian characters, I am in nowise surprised to see the Falcon (which shoots upward so high above the Chelonian) in its ascent passing close to and retaining much of the likeness of that less specialized and much less metamorphosed type. That the study of the modifications produced by metamorphosis of the primordial face is of the utmost importance to taxonomists is evident; and the vomer alone is, in this respect, worth more than all Mr. Garrod's muscles put together. In the Reptilian group the Chelonia are alone in possessing an azygous vomer; and only a minority of the bird class have the same character. Here, in the Falcon, this bone is not shaped like the proper ploughshare, but like that less common implement the breast-plongh, for sod-turning. The blade of this bone is roundly three-toothed, its shaft flat vertically, down-bent in front and lifted behind, and the handle is thick and forked. The blade is wedged behind in the maxillopalatine harmony, and between the ear-shaped maxillo-palatine lobes. The shaft divides the median nares, right and left; the two-toothed handle bites the palatine commissural plates ; it is fastened there by a wedge of bone, which has been driven in, as it were, on the right side. This wedge is the right mesopterygoid (mspg). In this type I have found no other vomerine bones.

The pterygoids (fig. $4, p g$ ) are even less specialized at this stage than those of the Cariama; they are larger relatively, have a less distinct auricular process (epg), and their abortively developed apex only appears on the right side as the mesopterygoid wedge (mspg).

The only difference between the palatines and those of Dicholophus is their greater shortness; also whilst the inner ridges end in the Falcon as a short interpalatine spur (ipa), those of the other bird are ragged and formless. In both cases the transpalatine region $\left(t_{p} a\right)$ is evenly rounded off, but the outer lobe is scooped below for the palatine muscles. In the jugum of the Cariama the elements once combined; but I suppose these were then the jugal process of the maxillary, the jugal itself, and the quadrato-jugal. These two latter are not separate, as far as I can see, in the Falcon, which thus 
agrees with a large number of the "Aves aëriæ," whereas in Hawks and Owls they are both present. But the most striking part of their palatine outworks is the huge maxillary $(m x)$; it is, relatively to the premaxillary, as extensively developed as in the Chelonia, although the dentary process of the latter bone overlaps it as in osseous Fishes, and, indeed, in birds generally.

These parts are builded together in a manner which would please the eye of an architect.

But the whole meaning of these parts can only be seen by the study of sections made in young skulls. In a nestling younger than the one from which the palatal view was taken, I have been able to decipher all those parts of the face in which the nasal capsules have their furniture disposed amongst and within the foremost facial bars.

In this type the nasal labyrinth enfolds itself and encloses its passages with solid cartilage to a very unusual extent. Here (Plate XXV. fig. 1, en) the external nasal opening is not a long slit, but a neat round opening; the rim is wrought, like the rim of a cup, and is almost closed by a finger-shaped projection from the alinasal turbinal (atb). This process looks outwards and backwards, and only leaves around it an oval chink. The whole alinasal region (figs. 1-3, aln) is formed into a pair of oblong oval pouches, like two carpels of an apocarpous fruit dehiscing; seen from below, there seem to be two cells left out of four; and the still persistent lanceolate prenasal cartilage $(p n)$ running from the base of the septum $(s n)$ carries out still further the similitude, it being in the likeness of the fruit-axis. Behind, at this most bulbous part, these nasal pouches are complete tubes, the floor having coalesced with the middle wall (fig. $3, a l n, s n$ ); this is shown in section (fig. 5), also the apposition of those parts further forwards (fig. 6).

When the septum is removed, to show the inner face of the turbinals, it is seen that the alinasal turbinal (fig. 2, atb) is a large leaf of cartilage, hollow outside and bulging within (see also sections, figs. $5 \& 6$ ). This leaf is attached to the outer wall by its upper edge, and is also confluent behind with the bulging floor, where that part rests on the nasal nerves $(n n)$. Over the hinder third the true "inferior turbinal" arises; this is at first a two-winged crest (fig. 5), but further backwards acquires the true type of the organ, as seen in the "Carinatæ" generally; it has nearly three coils (see fig. 2, $i t b$ ). The middle turbinal is merely represented by an irregular ridge on the fore face of the antorbital plate, and the upper turbinal by the coiling, on itself, of the aliethmoidal plates, exactly as in the Common Fowl (Phil. Trans.).

The septum nasi is connected by an uncleft isthmus of cartilage (fig. 4, sn) with the perpendicular ethmoid ; it is unusually deep and large for a bird (figs. 4-6). There is one septal fenestra $(s f)$ in addition to the "notch" between the septum and the ethmoid; this window is situate close behind the insertion of the alinasal bag. The hinder insertion of that bag is much thickened, and at this part the nasal branch of the orbito-nasal nerve (fig. $4, n n$ ) bores its way through the cartilage, piercing the alinasal, and burrowing in the septal cartilages; it soon gets below the septum (see figs. 2, 4, 5). Now if these sections be compared with the palatal view (Plate XXIV. fig. 4), and these by the reader with an adult skull before him, it will be easy to comprehend the compact and complex desmognathism of this type, a type having the most highly ossified and, in many 
respects, the most specialized skull to be seen amongst the Raptores. The broad foot of the vomer (Plate XXV. fig. 5, v) fits like a keystone between the large maxillo-palatine slabs $(m x p)$; and these are bound, externally, by the dentary plate and angle of the premaxillaries $(d p x)$. In front of the vomer (Plate XXIV. fig. 4) the maxillo-palatine plates meet, and afterwards coalesce. Ultimately, when all these structures, without and within, have coalesced by extended ossification, all but the vomerine undersetter, then the lateral halves of the face are indissolubly bound together, and form a structure most compact and strong.

On the Structure of the Skull in the Sparrow-Hawk (Accipiter nisus)*.

In greater feebleness of general structure the skull of this type is intermediate between that of the Falcon and the Cariama; but the leanings of the Hawk are not so much towards the latter as in the direction of that gigantic Vulturine Harrier the Secretary Bird (Gypogeranus). The skull of a partially fledged nestling yielded the results given in Plate XXV. figs. $7 \& 8$. Here we see at once things that agree better with the skull of the Cariama, and also things that are less in conformity with it than those just described in the Falcon: whilst the Cariama agrees with the Falcons, Eagles, and the more Aquiline types of Vultures in having the basipterygoids early arrested, the Sparrow-Hawk shows them as strong short spurs in the young (Plate XXV. fig. 7, bpg), and retains them as mammillary elevations in the adult. They are still more developed in the Harrier (Circus), more still in the Brahmany Kite (Haliastur indus), and perfectly functional in the Secretary. In Accipiter the parasphenoid (pas) is stout, and bevelled on each side by the under-gliding pterygo-palatines. The next median splint, the vomer$(v)$, is truly azygous, and is a long knife-blade at present; in the young it is neither bidentate behind nor pedate in front; it alters but little afterwards, and agrees in this respect with the whole Accipitrine division of the group.

The desmognathism is perfect, although, in the young bird, it is "imperfectly direct," as in the adult Cariama. Already the septum nasi is fast fusing with the solid fore end of the premaxillaries; and, behind, its nerve-bridges and connexion with the alæ nasi make it a fit wedge to fill up the space in front between the large lunate maxillopalatines $(m x p)$, which, lying back to back, of necessity leave an open space in front for the septum, and behind for the vomer. The premaxillaries form a less solid mass than in the Falcon; but this type is much more orthognathous than the Cariama. Whilst the Hawk agrees with the gallinaceous types in having a truly azygous vomer, it differs from them, and is in harmony with the huge groups of the Passerines and Pluvialines, in having a large mesopterygoid wedge differentiated from the fore end of the proper pterygoid (figs. $7 \& 8, m s p g, p g)$. As usual, the transpalatine $(t p a)$ is rounded off, more developed than in the Pluvialine types, but less than in the Passerines. The ethmo-palatine plates $(e p a)$ are thin, curved, pointed laminæ, embracing the head of the vomer; the interpalatine ridge (ipa) has no free spur. The prepalatine bars $(p r p a)$ reach as far forwards, or nearly, as the trabecular axis of the premaxillaries; they are thin laths of bone.

* For further details on this type of skull, see M. Mier. Journ. 1873, plates ₹. \& vi. pp. 45-50. In these plates. for ep read op. 
Behind we see that the large mesopterygoids $(m p g)$ appear at the mid line, between the postpalatine processes $(p t p a)$. Their general shape, as sharp wedges, is seen in the side view (fig. 8). The pterygoids ( $p g$ ) differ but little from those of the Cariama, being short, flattened out on the inside in front; whilst behind they send up a very rudimentary epipterygoid plate $(e p g)$. The extent of the median part of the maxillaries, the maxillo-palatine plates $(m x p)$, is very large, equal indeed, fore and aft, to what is seen in an ordinary mammal. They are spongy, have a somewhat lunate or, rather, ear-shaped form, and their hinder part forms a large free lobe, curving outwards.

In addition to the jugal process of the maxillary, there are two slender styles on each side, a jugal $(j)$ and a quadrato-jugal $(q j)$, and not merely one bone, as in the Falcon.

\section{On the Structure of the Face in Buzzards, Kites, and Harriers.}

Several subfamilies of the lesser rapacious birds range themselves under the Accipitrine type as a distinct form, and inferior to the Falconine. Their cranio-facial structures agree very closely with what is seen in the Eagles and the Aquiline Vultures.

The condition of the facial parts in a recently fledged Common Buzzard (Buteo vulgaris) is very instructive, and is representative of what may be found in a large number of Old-World Rapaces, excluding, of course, the culminating forms, the Falcons.

A large interorbital fenestra (Plate XXIV. fig. 9, iof) separates the ethmo-presphenoidal bar above from the ethmo-basisphenoidal bar below $(p e, b s)$, and the flat roof of the great ethmoid, covered by the frontals and nasals $(f, n)$, is rapidly becoming bony from the huge median centre $(p e)$. This roof sends backwards the normally ornithice spike over the olfactory nerve (1), which grooves the bony plate on each side. The coiled aliethmoid (ale), the representative of the upper turbinal mass of the mammal, is thus partly ossified.

The flat antorbital plate, or pars plana $(p p)$, which represents the middle turbinal, is already ossified, and has coalesced with the perpendicular plate or meso-ethmoid $(p e)$; it is roughly pentagonal in form.

But this orbito-nasal partition is a downward continuation of the ala growing from the roof, the aliethmoid: (ale); the two are connected by a narrowish band of cartilage: this band is separately ossified, forming an "upper ectethmoid" bone, as in the Passerinæ (Corvus). It lies under the roof, however, and does not stand out as a prefrontal mass, as in the Crow and its congeners.

The nasal nerve runs into the nose from the orbit, inside this bar, skirting the upper turbinal, and then sends most of its substance forwards and downwards (see dotted line in the figure) to the base of the septum nasi.

The notch which divides the true olfactory region from the septum nasi $(s n)$ is very large, runs obliquely forwards and upwards, and ends a little distance from the top; hence this cranio-facial cleft is imperfect. The septum itself, only partially ossified as yet, is differentiated into a nasal or trabecular, and an upper or true alinasal region, by a large, oval, internasal fenestra (inf). Below and in front of this space the septum is ossified as one large bone (lso), whilst the upper part is soft, except at the roof, behind; there is at that part an upper septo-nasal bone (uso). The large lower bone 
is burrowed by the nasal nerve; and above and in front of this burrowing there is a transverse septal knob, where the inturned alinasal fold joins on to the septum. On each side the large, spongy, pneumatic maxillo-palatines (mxp) flank the septum, and have the fore end of the knife-shaped vomer $(v)$ between them. The palatines $(p a)$, the mesopterygoids (mspg), and the pterygoids $(p g)$ conform very closely to those of the Sparrow-Hawk.

In the Harrier (Circus cyaneus) and in the Brahmany Kite (Hatiastur indus) I find a separate, thin, "median septo-maxillary," attached, vertically, to the upper edge of the vomer. It is very possible that this state of things may be merely the appearance of a second vomer; I am not certain on this point; parts primarily symmetrical do at times become azygous or median by the overgrowth of one and the arrest of the other, the stronger bone gaining the mid line, and dragging the feebler bone after it.

These feebler types have, as a rule, a flat superorbital on the free end of the long superorbital process of the lacrymal. In the Falcon the ossification is continuous along their frowning brow.

The reader is referred to Prof. Huxley's "Classification of Birds" (Proc. Zool. Soc. 1.867, p. 442, fig. 24) for the palatal view of the Secretary's skull: that figure is deficient; it should show a small knife-shaped vomer, like that of a Fowl. The whole skull of that bird comes very near to that of the Brahmany Kite (Haliastur indus) and to that of the Egyptian Kite (Elanus caruleus). Its general skeleton is hugely modified on account of its stilted Crane-like stature; legs of any indifferency would have asked for none of those specializations of shoulder and hip-girdle which we see in that type.

\section{On the Palatine Bones in Eagles and Vultures.}

I shall merely note a few things to be seen in these large groups of the gigantic Raptores.

In the Bateleur Eagle (Helotarsus ecaudatus) there is a small median palatine (Plate XXV. fig. 9, mspg) between the ethmo-palatine laminæ.

In Neophron percnopterus I find a delicate knife-shaped vomer (Plate XXV. figs. 14, $15, v)$, the right fork of which is evidently aborted by a small mesopterygoid (mspg); and besides this, on the same side, there is another granule of bone, belonging to the same region (fig. 16, mspg). At the end of vomer, thinned out, however, in front, there is a small medio-septomaxillary $(m s m x)$.

In Gyps fulvus there is an unlooked-for amount of differentiation of the palatine arch; for even in old birds a sharp sutural line runs obliquely two thirds across, almost separating the transpalatine (Plate XXV. figs. 17, 18, tpa) from the rest of the bar. Here also I find a strong wedge-shaped mesopterygoid ( $m s p g$ ) permanently distinct.

For the skull of Cathartes aura the reader is referred to Prof. Huxley's paper (op. cit. p. 440, fig. 22 ); it is an instance of "indirect desmognathism," the maxillo-palatines not being developed more mesiad than in Plovers and Pigeons; but the bond being formed of an ossified tract of the septum nasi and inturned alinasal fold, this forms a bony bridge similar to that seen in the Cariama; but there it is the anterior 
part of the alinasal fold. These South-American types agree together in the very limited ossification of the nasal sacs, so different from the Old-World Rapaces.

In the King Vulture (Sarcorhamphus papa) the palate agrees with that of its congener Cathartes (Plate XXV. fig. 19); but I find a small medio-palatine (mpa), and also much larger and more functional basipterygoids $(b p g)$. In this bird the Eustachian passages $(e u)$ open out into a very patulous, triangular fossa; and all the basicranial structures are very strongly soldered together. The basitemporals (bt) have also a large mammillate knob on each side for muscular attachment.

\section{On the Structure of the Skull in the Owls (Strigidæ).}

The Owls are the most distinct group of the Rapaces, and in respect of their basis cranii come very naturally after the Cathartidæ. They agree with the Cariama in their digestive organs, and, what is also quite unaccountable, with the Pigeons, in having a curious deficiency in the occipital arch, a hole, like an artificial pin-hole, being left unossified, as it was formerly non-chondrified, over the great cranio-spinal opening. The study of the skull of the Owls in nestlings and young fledglings is of great interest, these observations being made before the skull has become one light, spongy, undivided mass.

In a fledgling of the Barn-Owl (Aluco flammeus) the details can be well made out (Plate XXIV. fig. 5), and the likeness and unlikeness of the type to that of the highest, the Falcon (fig. 4), and the lowest, the Cariama (fig. 3), is clearly seen.

The relation of the pterygoids to the basipterygoid processes $(p g, b p g)$ is quite like what is seen in the King Vulture; but the parasphenoid (pas) is very swollen and is early fused with a very thick and spongy interorbital septum. Not only are the outworks of the ear of larger extent, but the tympanic cavity has large "anterior recesses" and great upper chambers, corresponding to the open gallery that connects the right and left chamber in the Crocodiles. The Barn-Owl has a chain of small tympanic ossicles, six on each side, running along the inferior surface of the junction of the "lower otic process" of the quadrate and the wing of the prootic, to which it is articulated.

This lower otic process is as large relatively, and as divergent inwards from the " upper otic process," as in the Frog; it turns, however, more backwards than in the Batrachian.

The orbital process, or blunt-pointed free pedicle of the mandibular suspensorium (quadrate), is far severed from the trabecular base, and turns forward as well as inwards. The rest of the mandibular arch is feeble; its united halves form an acute angle in Aluco flammeus, and a much wider angle in Asio and Strix. So it is with the palate, this part not being nearly so outspread in Aluco flammeus as in the other types. Still in this species the pterygoids $(p g)$ diverge very much, and articulate with basipterygoid processes (bpg) very far apart, on the massive parasphenoid (pas). The pterygoids are slender, sigmoid, and cultrate; they are toothed in front, and have a small epipterygoid crest $(e p g)$ behind. In this species the palatines $(p a)$ are almost parallel, and they are very contrary to most of the bones, being thin and lathy. In this species the palatines are as simple as in the Common Fowl, the transpalatine process being suppressed, and the muscular 
grooves almost invisible. In older birds a small interpalatine spur can be seen, but in the young it is not evident. The ethmo-palatines (fig. 7, epa) are very short, and backwardly placed; they are high, looking obliquely forwards and upwards, and become spongy; in front they send forwards a flat half-coiled horn of bone; this is lost as a separate process in the adult, for it coalesces with the much enlarged vomer, each process adding to the depth of its shelving sides, and leaving a large fossa above, which opens into most exquisite air-cells.

The palatines are kept apart by a triple wedge, the vomer $(v)$ below, and the earlycoalesced mesopterygoids (mspg) above. This structure can only be seen in very young birds before they leave the nest. Now the vomer is a smallish spindle; afterwards it is a large dagger-shaped bone, with a deeply sulcate upper edge.

The thin fibrous prepalatine bars (fig. 5, prpa) form rests for the huge, ear-shaped, swollen maxillo-palatines $(m x p)$; their tip articulates with the inside of the splintery palatine process of the premaxillary $(p p x)$. The dentary part of that bone $(d p x)$ is not strong, and the beak part is hollowed below. The fore end of the ossified septum nasi coalesces with the premaxillary, and thus an extensive bridge is formed over the anterior palatine space and under the external nostrils, the same as, but much more extensive than, that seen in the Cariama (fig. 3, aln), where the ossification is arrested.

The hollow part of the beak in front of the nostrils has a bony septum between its air-cavities, formed by the premaxillaries themselves $(p x)$, and lying in front of and below the true septum nasi.

A considerable chink, $\frac{1}{30}$ of an inch wide, separates the maxillo-palatines $(m x p)$; so that, notwithstanding their great size, these birds are only "indirectly desmognathous." The septum nasi is thoroughly ossified, but not the outer alæ. It is of great anteroposterior extent.

The orbital septum is a thick cushion of soft bone, very much bevelled away below, but running forwards at its upper part; this arises from the direction taken by the great cranio-facial cleft, which runs forward as well as upward.

The weak diverging jugal bars are composed of three elements, as in Accipiter ( $m x$; $j, q j$ ) ; both the premaxillary and the maxillary have an angular process.

But these three elements are not all that is to be seen in the jugal bar; for that additional bone which I have called the postmaxillary is here present (Plate XXIV. fig. 8, ptmx); it is a smallish oval grain of bone, and can be seen in young birds not long escaped from the nest. In this bird also can be seen an additional bone behind the orbit, the counterpart of the ichthyic postfrontal or "sphenotic." The lacrymal (partly shown in fig. $8, l$ ) is very large and spongy, and does not send out a superorbital process as in the "Diurnæ."

In the Long-horned Owl (Asio otus) the palatines are supplied with a large vomerine keystone (Plate XXV. fig. 10, v). Here the inner part of the palatine arch may have had a single medio-palatine, or a pair of mesopterygoids ; but they are not distinct, although the specimen was a bird of the first summer; these sutures are early lost in the BarnOwl; and the medio-palatine of the adult is often formed of two mesopterygoids in the young. I suspect it is so in this case.

SECOND SEI IES.-ZOOLOGY, VOL. I. 
The vomer $(v)$ wedges in between the small ethmo-palatine laminæ $(e p a)$; and above it is a similar bone, the median septo-maxillary $(m s m x)$ : both the bones are similar in shape; but the vomer lies behind the bone above it. In the large Ketupa ceylonensis there are two similar bones (Plate XXV. fig. 11, $v, m p a$ ); but they are much smaller, and the vomer is in front of the other, which is a medio-palatine.

In Athene noctua these parts are all coalesced together. The palatine keystone, made carinate by a small vomer, just shows traces of its sutural connexion with the ethmo-palatines. This bird has large superorbital processes to its frontals, not to its lacrymals.

In the Hooting-Owl (Strix stridula) these parts remain separate (Plate XXV. figs. 20, 21). There is a small vomer $(v)$, and over it a similar bone, as in Asio otus; both of these arrested bones are in front of the short ethmo-palatines $($ epa $)$; but behind these there is a veritable medio-palatine (fig. $20, m s p g$, fig. $21, m p a$ )* and the antero-superior ossicle $(m s m x)$ has the same position as the small median bone which $I$ have called the "median septo-maxillary" in the Harrier (Circus cyaneus).

This is the bone which may possibly be a rudiment of the vomer of the other side (right or left); for in the "Picidæ," certainly, I have seen submesial bones join the mid line; and the stronger push the weaker out of place.

In none of the Rapaces have I seen any remains of the paired "septo-maxillaries" so common in the Passerinæ, where they are small (although so large in Ophidia and Lacertilia). As a correlate of this state of things, the labial cartilages appear to be wholly suppressed in these birds.

In Strix stridula (Plate XXV. fig. 20) the transpalatine region $(t p a)$ is as well developed as in the Diưrnal types; altogether it has a most instructive skull, and one quite unrivalled for its swollen, spongy lightness of osseous tissue.

We have, even in this short survey of so small a tract of their structure, seen that the Rapacious birds have much in common, and that the least specialized, as the Cariama, marvellously wedges itself in among the roots of the most specialized of all, even the Falcons and the Owls.

On the Structure of the Skull in the Laughing-Gull (Gavia ridibunda).

Several years ago a friend supplied me with a goodly collection of the young of this species, and I took an early opportunity of working them out.

One of the first things which struck me was the Pluvialine character of these pulli, and this at once struck me as being completely in harmony with resemblances I had noted in these birds to the common Lapwing (Vanellus cristatus).

I am not sure which side of the boundary between the Plovers and Gulls one elegant type-the Pratincole (Glareola) - should be placed; nor whether any man knows the exact proportions of the Plover and of the 'T'ern it contains in its organization. The fact that Gulls are neither "Altrices," proper, nor true "Præcoces" makes their relation to the Pluvialine types the more instructive; for the amount of super-pluvialine metamorphosis is not great, although real and measurable.

* This bone has been lettered in two ways, by mistake; both mpa and mspg are correct, as a single mesopterygoid becomes a medio-palatine. 
My views as to these relationships were fairly pledged several years since (see "Gallinaceous Birds and Tinamous," Trans. Zool. Soc. vol. v. p. 150); and I was soon led to see how many large Families of Birds were constructed according to the pattern of the Plover*.

But this was only one among several nascent generalizations germinating in my head at the time; so that when Prof. Huxley's new ideas were given out, they fell into a receptive soil, so far as I was concerned.

In this, as in other branches of zoology and morphology, there has been for many years a remarkable harmony in our views; and nothing more struck and delighted me, in that coincidence, than my friend's commendation of one of the large groups that seemed to me to gather towards one poirt: I refer to the double "Gallo-Anserine" family.

That the embryology of both the Goose and Fowl was marvellously similar, I had then seen; but I was not aware how close the Palamedeas on one hand come to the Curassows and mound-making Megapods on the other.

But that which concerns us most at present is the huge number of birds with open palates ("Schizognathæ") that have either a filial relationship to the Plover, or are cousins-german to it.

It thus comes to pass that when once the structure of a Plover's skull is thoroughly understood, it serves as a norma to which the skulls of whole groups of birds can be brought for comparison.

This is true, not merely of the related Schizognathous birds, but also of those Grallæ which are desmognathous; for the likeness and the difference between the split skull of a fowl and the bound skull of a Palamedea is very similar to the likeness and the unlikeness of the skull of the Crane on the one hand, and of the Heron and Stork on the other.

There is one thing which is apt to mislead the zoologist in the consideration of the great group of "Carinate" birds; they, with the "Ratitx," are unconsciously compared with the whole of the Mammalia. At first view it might be thought that the Ratitx equalled, as a group, the "non-placental" mammals, and the Carinatæ the placental; but the groups are not properly comparable; the Carinate birds, notwithstanding their number and variety, could not be equalled with more than two or three at most of the Mammalian Orders, and not with the whole herd of the Placentalia.

Those morphological modifications which lie at the root of the diverse specializations of the Carinate birds take place, as we pass from type to type, in the gentlest manner; all the types of skull may be seen to spring from a fundamental form, rich in Rhynchosaurian, and even in Batrachian characters. Such a skull the Ratitæ all possess.

After analyzing a skull of this kind, and finding how it is built up, as it were, according to old styles of skull-architecture, familiar to him who knows the lower or coldblooded types, the morphologist is brought to a stand; for here the lines of life diverge.

* This was handled excellently by Prof. Huxley in his "Classification of Birds" (Proc. Zool. Soc. 1867, pp. 496431 and $456-458)$. 
Standing in the ways to see and to judge which is the right path for each Carinate type, the worker finds it no "far call" from the order-joining Tinamous to the Plovers on one hand, and the Fowls on the other."

The sucker which grows into the Passerine tree is not so clearly discernible in the Tinamine stock-in such Tinamous as now exist; but just above where the fork is, the Hemipods are unmistakable in their relation to the harsh-voiced Passerines of the southern hemisphere.

Above, when the Tinamine branch forks amongst types of no great elevation, and in which the Dromæognathous skull has passed into the Schizognathous, we see the nobler forms ("Aves aëriæ") just superimposed upon and, as it were, growing from the lower forms-the "Præcoces."

From above the Sand-Plover arose the Pigeon, in its older and now extinct forms; and from above old types of the Gallinaces the fundamental or stock-form of the Rapacious bird sprung. The genus Dicholophus is but little changed from such a primitive plunderer.

Skull of Gavia ridibunda. 1st stage.

There were five stages of the young of the Laughing-Gull amongst those examined by me; to these are added the adult; the largest young were just ready for flight, the smallest only about a week old.

After these had been worked out, I obtained half-ripe young of the Silvery Gull (Larus argentatus) from the "Lesser Orme's Head," near Llandudno ; but these, although studied in various ways, have not been wholly worked out by me; their condition at that early stage differs but little from embryos of the Common Fowl (see Phil. Trans. 1869, plate lxxxii., 3rd stage).

In the first stage the primordial skull (chondrocranium) is thoroughly formed; it has also most of the osseous centres commenced, and some of them ankylosed to their neighbours. The occipital region is very instructive; the basiocciptal (Plate XXVI. fig. 2, bo) is a long oval piece, enclosing the starved notochord, and separated by large cartilaginous tracts from the lateral pieces, the exoccipitals $(e o)$. These bones are very irregular pentagons; they are creeping over the hinder part of the auditory capsule, the canals of which are seen shining through the clear cartilage (figs. 1-3, hsc, psc). The exoccipitals already half enclose the foramen magnum $(f m)$; but a good space exists between them and the double keystone piece, the superoccipital (so). This latter bone is composed of two halves, which are only half-soldered together; above they are quite distinct. They now form a very elegant bony plate with many sides, some having a scooped and others a rounded outline.

The archway of the foramen magnum is finished by the concave margin of the coalesced part; above, behind, and below the parietals $(p)$, the margin is a bifoil. Between these margins the bone has an indrawn waist; on each side, at this part, there is a non-cartilaginous space-a "fenestra" or "fontanelle," the lateral occipital fontanelle so familiar to osteologists in Pluvialine and Anserine types (see in Vanellus cristatus, Trans. Zool. Soc. vol. v. plate xxxvii. figs. 1, 2, \& 4, l.o.f). 
Outside these spaces the bone is ear-shaped, the substance of it spreading towards the ear-capsule.

These capsules are very large, and being impacted into or, at least, grafted upon the large occipital arch and wall, appear very considerably in the back of the head.

Ossification has appeared in them, and the largest bony piece, the prootic (pro), is seen behind the quadrate $(q)$ in the lateral view (fig. 1 ); the other centres will be described in more advanced stages, but the opisthotic is already well developed, although much smaller than the prootic; the epiotic has not yet appeared.

The common sphenoidal region is at this stage a part full of interest to the morphologist. The three divisions of the great winged parasphenoid, although ankylosed, are very evident. They are the rostral portion in front (figs. $1 \& 2$, pas), and the basitemporal plates $(b t)$ behind. These three bones are setting up ossification in the overlying chondrocranium, although developed at first as parostoses and quite independent of it.

As in the Ichthyopsida, these primordial splints are very large in relation to the rest of the skull. That this should be so, shows how little the Bird is related to the ordinary Lacertian type of Reptile, where the only remnant (not always present) of the parasphenoid is the anterior part. On each side of the scooped (Eustachian) part of the median bone there is a cartilaginous bud; this is the basipterygoid process (bpg), a typically Pluvialine structure.

Behind these knobs the bone spreads into large wings that enclose the "anterior tympanic recesses." Beneath these imperfect trumpets lie the basitemporal bones $(b t)$; they have nearly melted into each other at the mid line, and above they are being soldered to the tympanic wings of the parasphenoid.

But the overlying cartilage around the pituitary body and beneath the optic nerve (2) has become osseous directly from the bone beneath ; this is the true basisphenoid (bs); the square inturned large alisphenoids $(a l s)$ are also ossified.

A large bony leaf is seen in front of the orbital septum; it is trifoliate behind, and does not nearly reach the membranous window between the eyes (iof).

In the figure (fig. 1) the septal portion of the nasal labyrinth has been cut away (see this part from below in fig. 7); this is at the cranio-facial " notch," and the part in front is only supplied by the orbito-nasal branch of the fifth nerve, and not by the olfactory.

This bony plate is the perpendicular or mesethmoid $(p e)$; its huge size has relation to the abortive development of the anterior sphenoid, and its bony matter will not cease to grow until it has reached that of the posterior sphenoid (bs) beneath the optic nerve (2).

Nothing but development could possibly throw the least light upon this anomaly; there are no orbito-sphenoidal alæ, and the presphenoid is merely that bar of cartilage, afterwards bone, which is seen bounding the posterior half of the interorbital fenestra (iof) behind; it reaches neither the top nor the bottom of the interorbital chondrocranium.

The top of the chondrocranium finishes behind in a median projection, behind and between the upper turbinal scrolls (aliethmoids); this is a rudiment of that cartilaginous 
cloth which is thrown over the brain-sae in the Salmon and Polypterus (see my memoir on the "Salmon's Skull," Phil. Trans. 1873, plate v. t.cr), the tegmen cranii.

The reason for the membranous space between the eyes is not primarily teleological. Nature is not husbanding her cartilage as being poor in that substance; it is a secondary cleft, tending to divide the overlying ethmoidal structures from the crest developed on the coalesced trabeculæ.

The roofing bones are seen to be well developed, the frontals, parietals, and squamosals $(f, p, s q)$; the latter are elegant subfalcate bones, running far along the postorbital part of the frontals, and somewhat trilobate below, where they clamp the ear-capsule. The columella $(s t)$ is ossified in its medio-stapedial region, and the quadrate also, not its pedicle or orbital process; its otic facets and its double lower condyles are all soft as yet.

In this stage I have only brought into view the hinder facial parts; the pterygoid $(p g)$ has now a long splint-like process which reaches to the corresponding crus of the vomer, not here shown, but seen in fig. 12, $v$ *

Afterwards the absorbents fret a suture across the base of this spur, and convert it into a separate mesopterygoid, which, however, is only distinct for a few weeks, for it soon coalesces with the postero-superior edge of the palatine.

The relation of the jugal to the quadrato-jugal, and of the latter to the quadrate, into which its hooked end is inserted, is here shown (fig. $1, j, q j, q$ ).

The long dentary, which has coalesced with its fellow at the "mentum," has been removed, but the proximal part of the free mandible is shown (fig. 4, outside; fig. 5, inside).

Meckel's cartilage ( $m k$ ) is still large, and runs far forwards; its articular end, with its short Pluvialine posterior and internal angular processes (pag, iag), is ossifying; there is an endosteal patch and a long ectosteal plate (ar).

I see no separate coronoid, a bone often indistinct in birds; but the splenial, angular, and surangular $(s p, a g, s a g)$ are large and still free.

In these long-faced birds the glossal portions of the hyoid are more than their hypohyals; they deserve the name here of cerato-hyals (fig. 6,chy); they are unossified and confluent.

There is a common cartilaginous basibranchial element $(b b r)$, pointed and delicate behind, and only the proximal part of the first branchial arch (thyro-hyals, brs) is ossified; the dorsal element is long, slender, and soft.

The nasal cartilages have been cut away and turned on their dorsal face to show their laminar outgrowths (fig. 7); the section was made close behind the hinge or notch (see fig. 1), and a line in front of the meso-ethmoidal bony centre (pe).

Unlike what we see in Mammals, the turbinal that figures most largely here is that belonging to the alæ nasi. This alinasal turbinal $(a t b)$ is here a simple foliaceous outgrowth (see it in section, fig. 8). Behind this, and rising above it, is the inferior turbinal $(i t b)$. This is a simple plate at its commencement; further back it is coiled upon jtself. In most birds this scroll has two coils.

* This is a primordial relation of the pterygoid and the vomer; it is found in the lowest Urodela, to say nothing of the Rhynchosauria. Sce Fuxley, Proc. Zcol. Soc. 1874, pl. xxix., and Günther, Phil. Trans. 1867, pl. i. fig. 2. 
Behind the inferior turbinal, and also above it, is the coil of the upper turbinal ( $u t b)$, which is merely the aliethmoidal region of the nasal roof turned in upon itself.

This is represented as cut through the middle in the inverted figure (fig. 7, utb); this and the front wall of the pars plana (see fig. 15), which has no definite middle turbinal on it, form the proper olfactory territory.

\section{Skull of Gavia ridibunda. 2nd stage.}

A somewhat more advanced stage (Plate XXVI. fig. 11) is shown in section as far as to the cranio-facial isthmus $(c f c)$; this figure supplies the deficiency of the last in not showing a sectional view; and it also shows some advance in the osseous deposits.

This section has been made a little to the near side of the mid line, and shows the parasphenoid and basipterygoid and the whole interorbital septum uninjured. The backtilted large auditory capsule is seen to lie both on and in the occipital arch; for the bony matter creeping over the junction of the anterior and posterior semicircular canals is not, in the bird, a large separate epiotic bone as in reptiles; a rudiment appears afterwards in this bird as in some others; but at present the super- and exoccipital is largely walling in the otic mass.

The main periotic centre, the prootic ( pro), is now a large oblong bone, and separated by the unossified auditory crest from the alisphenoid (als), and by synchondrosis below from the basisphenoid $(b s)$ and the basioccipital $(b o)$. The auditory nerve, or portio mollis, pierces it, as also the portio dura, or facial nerve. Outside these foramina the bone is scooped for the superincumbent brain, and becomes a mere crest; the edge itself is still soft.

A clear wedge of bone is seen between the prootic and the exocciptal $(e o)$; this is the opisthotic $(o p)$; in the specimen it was becoming ankylosed to the prootic, but I have diagrammatically given it a sharp suture from observation of the first stage.

The large passage (8) between the exoccipital and the opisthotic is for the glossopharyngeal and vagus nerves; the anterior and posterior condyloid foramina (9) are seen on the edge of the exoccipital.

A large unossified space still exists on the crown of the arch of the anterior semicircular canal, and also in the recess for the cerebellar flosculus below it. If the bony matter from the superoccipital had been somewhat less, then this space would have corresponded exactly to the region occupied by the epiotic bone in the Reptiles; its rudiment has not yet appeared in the Gull.

The lozenge-shaped basioccipital is nearing the side piece $(b o, e o)$; but there is a large spheno-occipital synchondrosis, underfloored by the basitemporal plate $(b t)$.

From the great submucous bones, the parasphenoid proper, and the basitemporals $(p a s, b t)$, an upgrowth of bone has taken place, metamorphosing the overlying chondroeranium.

This bone, the basisphenoid (bs), underprops the optic nerves at their exit, and embraces the dipping pituitary body, which passes down, as in osseous Fishes, to lie on the submucous bony tract; in the chondrocranium the pituitary space is open.

Into this pouched space the internal carotid (ic) enters; behind this space the cerebral 
mass lies on a shelving wall, the postpituitary wall, a scooped and slanting tract of bone, split at the mid line, from which the notochord has retreated. This fissure is the remains of the posterior basicranial fontanelle of the Reptile.

The prepituitary region has the anterior clinoid wall reaching the bony alisphenoid $(a l s)$, and a pinched front portion, which forms the postero-inferior angle of the interorbital plate, and which afterwards coalesces with the huge perpendicular ethmoid below the presphenoid.

This great mesethmoidal plate has increased in size, and is growing into the frontal region. The frontals themselves at present fail to wall in the space caused by the abortion of the orbito-sphenoids in the chondrocranium; there is, therefore, a postorbital fontanelle $(p o)$.

The subfalcate squamosal helps the alisphenoid $(s q, a l s)$ to finish the side walls; it clamps the prootic, overlies the alisphenoid, reaches the frontal, and supplements the parietal $(p)^{*}$.

\section{Skull of Gavia ridibunda. 3rd stage.}

This stage, in pulli a few days older than the last, has been worked out principally to display the exquisite architecture of the great skull-floor, including the occipital, temporal, and posterior sphenoidal regions.

At this stage we see best this most curious piece of morphological mosaic, not quite unlike the wall-work of the test of an Echinus, but of a more complex type by far, and yet having fewer parts as far as mere number goes.

Indeed two very distinct strata are condensed and calcified to produce these results; and this difference is indicated in the figures by the colouring of the inner stratum, formed by ossification of the chondrocranium, and the outer, which is the inner stratum of the submucous connective web, is left uncoloured.

The first thing that strikes the eye in the under view is the long bony dagger and the deltoid bone which lies beneath and behind it. These divisions of the ichthyic parasphenoid are the rostrum and the basitemporals (Plate XXVII. figs. 1-3, pas, bt); on each side the rostrum widens between the basipterygoid cartilages (bpg), which are lessening; at the mid line it is scooped correlative to the meeting together of the right and left Eustachian tubes $(e u)$, and behind it simulates the basitemporal wings, widening and spreading.

These hinder wings form the " anterior tympanic recess" (atr, ppg): they are long, falcate, notched, and grooved plates of bone, and with the help of the underlying deltoid plate, the coalesced basitemporals (bt), they form a pair of very elegant bony trumpets leading into the drum of the ear, and are a specialization of the first visceral

\footnotetext{
* One of the older antomists (Owen), not seeing the squamosal in the inside of the struthious skull, took one of his remarkable intellectual leaps, and supposed that it was always absent from that part, a hard thing to find in any of the " Carinatæ."

This great theorist wanted the bone on the outside and further down for transcendental uses; it, however, refuses to leave its own supratemporal region, for it must be ready to graft itself on the auditory mass in all the hot-blooded Vertebrata.
} 
cleft. The hinder angles of the basitemporal plate are greatly produced, forming horns that underlie the exoccipitals, whilst the posterior concave edge has lying on it the fore end of the basioccipital (bo).

This latter bone has on each side, between it and the paired exoccipitals, a reentering angle of soft cartilage in front; but behind the three meet in the very substance of the transversely oval occipital condyle; here, in meeting, they form a suture like a leech-bite.

For the most part the occipital arch is well ossified (Plate XXVII. figs. 1-4); but the whole of the outer edge of this transversely crested structure is still unossified, the cartilage not merely existing on the tympanic wings of the exoccipitals, but also on the lower half of the superoccipital ridge $(t e o, s o)$. The original suture between the two superoccipitals is still visible above; but the "lateral occipital fontanelles" are nearly filled in by bone on each side the narrow waist of the median part of the keystone.

We note here already the partial obliteration of the two very important Pluvialine characters in these Sea-Mew chicks, namely, the basipterygoids and these occipital windows. Here specialization has taken place in two ways :-first, by arrest and absorption; and secondly, by the secondary covering in of a region not filled in by the chondrocranium.

The next important point to be noticed in these chicks of the third stage is the recollection, as it were, of the epiotics left out in the first growth of bony territories; they are, however, very small, and broken up into two or even three subcentres (Plate XXVII. figs. $2,5, \& 6, e p$ ).

This is seen many a time in ornithic morphology; the bones which get the first start in growth are large, whilst those which lose it are small, feeble, and overshadowed.

The upper view of the skull-base (fig. 2) shows well the round, deep, pituitary cup, pierced below by the internal carotids $(i c)$; also the slit below the hinder pituitary wall, which is the old gap caused by the retirement of the notochord. The elegant basioccipital lozenge somewhat wedges itself into the end of the large, long, compound basisphenoid.

But perhaps the most notable bones of all are the prootics; immense are they if compared with those of the mammal. They are scooped laterally for the brain, and have a lunate notch in front, which by a similar notch in the alisphenoid (als) becomes the foramen ovale (5).

The prootics tilt themselves back to such a degree that the great anterior semicircular canal is thrown, at its junction with the posterior canal, into the fore edge of the superoccipital (figs. 4 \& 5 , asc, so).

If this figure (2) be compared with the rest, it will be seen how neat is the carpentry by which the great ethmo-trabecular plate rests in the grooved upper surface of the parasphenoidal rostrum ( $p a s)$.

There it stands as a fixture; but this plate, the great meso-ethmoid, is almost sawn through from below in front of the rostrum, and its under beam is the light and loosely braced romer. 
Skull of Gavia ridibunda. 4th stage.

A little older than the last, the young of this stage yielded me the perfect longitudinally vertical section (Plate XXVI. fig. 12) now to be described: it runs close after and further illustrates the third stage.

The first sight of this object, and indeed of its figure, suggests feathery lightness; and the whole sum of its specialization, as compared with what is seen in the lower classes of Vertebrata, may be taken as typical of this group (the Carinatæ), in which the Reptile so marvellously culminates.

The actual brain-cavity only occupies one third of the entire length of the head; the nasal region proper, where the olfactory nerves are distributed, is exactly in the middle; the ear-capsules run into the hinder arch; and the eyes are fairly halfway between the other sense-capsules.

The great mesethmoid ( $p e$ ) has now reached the interorbital fenestra (iof) above, and behind it the cartilage ends in a retral spike, and in a groove below this lies the olfactory crus.

Then in front of that bony plate we see how the cranio-facial axis has been gnawed away, and a main and a lesser notch are seen leaving still a thick cartilaginous isthmus connecting the small septum nasi $(s n)$ with the main ethmoid.

In front of the former plate there is a large open gap before we reach the short, solid, hooked end of the premaxillary $(p x)$.

The feeble maxillary $(m x)$ is left in situ, and its maxillo-palatine plate $(m x p)$ is seen rising obliquely and leaf-like, on each side of the cranio-facial notch; inside of it is the forked and notched double vomer $(v)$; the rest of the face has been removed.

Behind, we see what has been already described in the second stage (compare figs. 11 \& 12), but with this difference, namely, that the bony territories are not hedged in with cartilaginous balks, but have their margins edge to edge.

The prootic is still distinct; but the epiotic fragments are now lost in the coadapted faces of the prootic and superoccipital; also the opisthotic has coalesced with the prootic and exoccipital.

The base of the cranial cavity is an ascending floor, concave below and behind, and convex as it begins to close in in front: the brain sits on the rounded upper edge of the presphenoid in front (Plate XXVI. figs. $16 \& 17, p s$ ).

Here the floor is the original membrano-cranium, the cartilage being stunted in this part; and any orbito-sphenoidal bones are merely such osseous centres as appear in the fontanelle. In the Fowl there are two on each side, supplemented by the orbital plate of the frontal. I see no evidence of any distinct centre here in this species; in the old bird the bony matter merely runs a little way into the fontanelle from the presphenoid.

\section{Skull of Gavia ridibunda. 5th stage.}

In these ripe chicks the sutures are becoming obliterated fast, especially those of the ossified chondrocranium; but there are still many clear divisional lines in the investing or outer part of the skull. 
The occipito-otic region is now one large shell of bone (Plate XXVII. figs. 7-10); in the hind region (fig. 16) the "lateral occipital fontanelles" (lof) are still open.

The basitemporal plate (fig. 9, $b t$ ) has now obtained its perfect form ; it is subtriangular, but the sides are convex, and the base is emarginate, and it has ear-like processes at its angles; these help to floor in the tympanic cavity. From the parasphenoidal rostrum (pas) the basipterygoids have disappeared, so that the Pluvialine stage has been passed in this part of the skull.

All the elements of the face are very slender and elastic, both those of the outer and also those of the inner series. The great perpendicular ethmoid ( $p e$ ) has reached the "notch" in front and above, and has nearly met the basisphenoid behind and below. There are still large postorbital and a large interorbital fenestra ( $p o f$, iof).

The nasal cartilages (the fore part of which had been removed in the specimen figured) are all cartilaginous, with the exception of the back wall or pars plana $(p p)$, which is made bony by a centre of its own.

Outside this there is an anvil-shaped lacrymal, Pluvialine in form, but answering to that of the larger types; its lower erus rests upon the outstretched antorbital plate (Plate XXIV. fig. 7, $l, p p$ ). The upper turbinal coil (aliethmoid) divides the groove for the olfactory nerve from that for the trabecular or naso-orbital.

The nasal processes of the premaxillaries were laid upon and wedged in between the upper plate of the nasals $(n p x, n)$. The upper plate of the nasals lies upon and is wedged in between the frontals $(n, f)$. The frontals are sinuously applied, behind, to the fore margin of the parietals $(f, p)$; this harmony-suture is the "coronal" of human anatomy. A "sagittal suture" runs along the whole skull and face, from the fore end of the nasal fossa, where the premaxillaries are soldered together, up to the notch in the upper surface of the superoccipital (fig. 10, so), the remains of the divisional line of its two primary halves.

The falcate squamosal $(s q)$ elegantly binds the whole cranial cavity together on each side; it runs upwards and downwards obliquely, behind, lying like a tile over the slanting occipital edge.

The nasals, as is the wont of the Pluvialine types, are sharply split into two crura (figs. $7 \& 8, n$ ). These run forwards, tying down the upper and lower branches of the premaxillaries $(n, n p x, d p x)$.

The pterygoids $(p g)$ are long, slender, and inbent. They are pedate behind, having an epipterygoid process, with an oval hollow above; and the proper end of the bone has an acetabular facet; both these embrace similar convexities on the fore margin of the quadrate $(q)$.

In front the pterygoid, having lost its mesopterygoid spike, which is now part of the palatine, fits, by a short tooth, into a shallow socket in the end of the palatine $(p a)$. In front, the palatine is a long, slender needle of bone, which is now tied to, and afterwards anchyloses with, similar needles, namely, the fore part of the maxillary $(m x)$ and the palatal process of the premaxillary $(p p x)$.

The outer edge of the two-keeled hinder part of the palatine has no more outgrowth as a proper transpalatine portion than the Plovers. (See my "Gallinaceous Birds and 
Tinamous," Trans. Zool. Soc. vol. v. plate xxxvii. figs. 1-5, for views of the skull of Vanellus cristatus, useful for the whole comparison between the Larine and Pluvialine skulls.)

The solid part of the premaxillaries is short. The maxillary widens at its middle, to form the elegant spoon-shaped maxillo-palatine process (mxp), which is obliquely placed, and has its "bowl" outside. The rest of that bone and the two pairs of jugals $(j, q j)$ are very slender spicules of bone.

The vomer (Plate XXVII. figs. $9 \& 9 a, v$ ) has the form so common in Pluvialine, Gruine, Ralline, Alcine, and Ardeine types; it is formed of two lanceolate centres that unite for their anterior two thirds by a sharpish angle. They become carinate below, and the carina is, in the young bird (fig. 9a), divided into two tracts. These afterwards are joined by fresh bone into one keel, which forks where the bone forks to form the crura that unite with the under surface of that part of the palatine which was the distinct meso. pterygoid bone.

The very pluvialine mandible (fig. 7, $d, a r$ ) has still a suture where the anterior and posterior parts unite; there is also an oval fenestra in front of the hinge.

\section{Skull of Gavia ridibunda. 6th stage.}

In the skull of the oldest specimen I have examined of this species the occipital fenestræ and the basipterygoids are entirely gone. The bone is light and thin, but rather dense; scarcely a trace of suture is to be seen-for instance, only above the cranio-facial hinge. The only bones free are the vomer, the quadrates, and the mandible. The latter bone has its sutures between the dentary and the hinder part persistent.

The nasal capsules are only ossified in the olfactory region (aliethmoid and pars plana); the vestibular cartilages remain soft, viz. the aliseptal with its inferior turbinal, and the alinasal with its turbinal.

But there is a structure of intense interest attached to the outturned end of the pars plana, and not differentiated from it in the cartilaginous state ; this is the "os uncinatum" (Plate XXVII. fig. 11, ou). This is a small triangular wedge of bone which rests upon the zygoma. It is well shown in the Albatross (Diomedea). I have lately described it in Dicholophus; traces of it occur in Alca torda and Uria troile; but its highest development is found in certain arboreal birds-Plantain-eaters, Parrots, \&c.

This bone is the ethmo-palatine, or joining-piece between the trabecula and palatine in front, and belongs to the same category as the basipterygoid.

On the roof of the skull large and elegant fossæ exist, on which lie the long, tongueshaped supraorbital or nasal glands. In old birds the two long ceratohyals are only soft at their apex or ventral extremity; they ossify to a great extent, ankylose in the fore part, then are somewhat bowed out apart, and then come close together in front of the basihyal. This latter bone sends osseous matter into more than the front half of the urohyal. The lower thyrohyals are ossified. The upper and more slender pieces are half soft below and at the upper ends.

But little difference would be found between this bird in its development and the 
growing young of a species of Podiceps, Colymbus, Alca, or Uria; they all specialize by passing just a stage or so beyond the simple Pluvialine pattern, but in different degrees. The Petrels are close congeners of the Gulls; many of the smaller kinds retain their basipterygoids. A large number of water-birds keep their "lateral occipital fontanelles" open throughout life. (See, on the Pluvialine types, Huxley, Proc. Zool. Soc. 1867, pp. 426-431.)

\section{DESCRIPTION OF THE PLATES.}

\section{Plate XX.}

Fig. 1. Vertical section through head of embryo Fowl (Gallus domesticus), about the beginning of the sixth day of incubation. $\times 7$ diameters.

Fig. 2. The same, taken further back through the eyeballs and nasal sacs. $\quad \times 7$ diameters.

Fig. 3. The same, behind the nasal walls. $\times 7$ diameters.

Fig. 4. Part of same section. $\times 27$ diameters.

Fig. 5. A section further back, through the eyes, pituitary space, and lower jaw. $\quad \times 7$ diameters.

Fig. 6. Section through ear-sacs of the same embryo. $\times 7$ diameters.

Fig. 7. A longitudinally vertical section of the hind face of an embryo of the House-Martin (Chelidon urbica). $\times 15$ diameters.

Fig. 8. Inner view of auditory structure and mandible in a fledgling Carrion-Crow (Corvus corone). $\times 3$ diameters.

Fig. 9. Os quadratum and stapes of adult Jackdaw (Corvus monedula). $\quad \times 6$ diameters.

Fig. 10. Stapes of Piping-Crow (Gymnorhina tibicen), inner view. $\times 10$ diameters.

Fig. 11. The same, edge view. $\times 10$ diameters.

Fig. 12. Palatine view of skull of Starling (Sturnus vulgaris). $\quad \times 4$ diameters.

Fig. 13. A species of Cardinal (Cardinalis, ? sp.). $\quad \times 5 \frac{1}{2}$ diameters.

\section{Plate XXI.}

Fig. 1. Palate of embryo of Brown linnet (Linota cannabina) of the sixth day of incubation. $\times 15$ diameters.

Fig. 2. Part of same. $\times 150$ diameters.

Fig. 3. Part of embryo of same bird, seventh day of incubation. $\quad \times 20$ diameters.

Fig. 4. Vomer and part of palatines of a fledgling Sparrow (Passer domesticus), seen from above. $\times 4 \frac{1}{2}$ diameters. 
Fig. 5. Palate of common Wren (Troglodytes vulgaris). $\times 5 \frac{1}{2}$ diameters.

Fig. 6. Part of same. $\times 11$ diameters.

Fig. 7 . Side view of face of the Wren. $\times 5 \frac{1}{2}$ diameters.

Fig. 8. Palate of adult Goatsucker (Caprimulgus europaus). $\quad \times 2 \frac{1}{2}$ diameters.

Fig. 9. Part of same, seen from above. $\times 4 \frac{1}{2}$ diameters.

Fig. 10. Part of face of same bird, upper view. $\quad \times 2 \frac{1}{2}$ diameters.

Fig. 11. Part of palate of young Goatsucker, seen from above. $\times 4$ diameters.

\section{Plate XXII.}

Fig. 1. Palate of a still younger Goatsucker (Caprimulgus europceus) $. \quad \times 4$ diameters.

Fig. 2. Palate of Humming-bird (Patagona gigas). $\times 3 \frac{1}{3}$ diameters.

Fig. 3. Part of same view. $\times 6 \frac{2}{3}$ diameters.

Fig. 4. The same, seen obliquely. $\times 6 \frac{2}{3}$ diameters.

Fig. 5. Cranium of same bird, seen from above. $\times 3 \frac{1}{3}$ diameters.

Fig. 6. Part of same, side view. $\times 3 \frac{1}{3}$ diameters.

Fig. 7. Hyoid bones of same bird. $\times 6 \frac{2}{3}$ diameters.

Fig. 8. Palate of a nestling Humming-bird (? Lampornis) from Barbadoes. $\quad \times 6 \frac{2}{3}$ diameters.

Fig. 9. Part of same. $\times 10$ diameters.

Fig. 10. Part of same, seen from above. $\times 10$ diameters.

\section{Plate XXIII.}

Fig. 1. Palate of Scythrops nove-hollandie. $\times 2 \frac{1}{3}$ diameters.

Fig. 2. Section of palatine bones of the same bird. $\times 2 \frac{1}{3}$ diameters.

Fig. 3. Side view of face of same bird. $\times 2 \frac{1}{3}$ diameters.

Fig. 4. Palate of Megalama asiatica. $\quad \times 3$ diameters.

Fig. 5. Side view of face of same. $\times 3$ diameters.

Fig. 6. Palate of Podargus. $\times 1 \frac{1}{4}$ diameter.

Fig. 7. Side view of skull of same. $\times 1 \frac{1}{4}$ diameter.

Fig. 8. Palate of same, with lower plate removed, seen from below. $\times 2 \frac{1}{3}$ diameters.

Fig. 9. Side view of palate of same. $\times 2 \frac{1}{3}$ diameters.

Fig. 10. Stapes of same, outer view. $\times 7 \frac{1}{2}$ diameters.

Fig. 11. The same, inner view. $\times 7 \frac{1}{2}$ diameters.

\section{Plate XXIV.}

Fig. 1. Skull of Gyps fulvus, from above. $\frac{4}{3}$ nat. size.

Fig. 2. Skull of Dicholophus cristatus, from above. $\frac{4}{5}$ nat. size.

Fig. 2a. Part of side view of the same skull. $\times 2$ diameters.

Fig. 3. Palate of same. $\times 1 \frac{1}{2}$ diameter.

Fig. 3a. Vomer of same. $\times 3$ diameters.

Fig. 4. Palate of Falco tinnunculus (nestling). $\quad \times 2$ diameters.

Fig. 5. Palate of Aluco flammeus (fledgling). $\quad \times 2$ diameters.

Fig. 6. Part of same, from below. $\times 4$ diameters.

Fig. 7. The same, from above. $\times 4$ diameters.

Fig. 8. Part of same skull, side view. $\times 4$ diameters.

Fig. 9. Skull of Buteo vulgaris (recently fledged), part of side view. $\times 1 \frac{2}{3}$ diameter. 


\section{Plate XXV.}

Fig. 1. Upper beak and nasal opening of Falco tinnunculus (nestling). $\quad \times 3$ diameters.

Fig. 2. The same in section, seen from the inside, and half the inferior turbinal showing. $\times 3$ diameters.

Fig. 3. Nasal capsule of same, with bones removed, from below. $\times 3$ diameters.

Fig. 4. The same in longitudinal section. $\times 3$ diameters.

Fig. 5. Transverse section of same, through the beginning of the inferior turbinal. $\quad \times 6$ diameters.

Fig. 6. Transverse section of same, through alæ nasi. $\times 6$ diameters.

Fig. 7. Palate of Accipiter nisus (fledgling). $\times 4$ diameters.

Fig. 8. Part of same, side view. $\times 4$ diameters.

Fig. 9. Part of palate of Helotarsus ecaudatus. Nat. size.

Fig. 10. Part of palate of Asio otus, lower view. $\times 3$ diameters.

Fig. 11. Similar figure of Ketupa ceylonensis. $\quad \times 2$ diameters.

Fig. 12. Vomer of Falco peregrinus (?), side view. $\times 3$ diameters.

Fig. 13. The same, under view. $\times 3$ diameters.

Fig. 14. Vomer of Neophron percnopterus, from below. $\times 3$ diameters.

Fig. 15. The same, side view. $\times 3$ diameters.

Fig. 16. Pterygoid of same bird. $\times 3$ diameters.

Fig. 17. Part of palatine of Gyps fulvus, upper view. Nat. size.

Fig. 18. The same, from below. Nat. size.

Fig. 19. Palate (part) of Sarcorhamphus papa, from below. Nat. size.

Fig. 20. The same in Strix stridula. $\times 2$ diameters.

Fig. 21. Part of same, oblique view. $\times 4$ diameters.

Note.-The letters mspg in fig. 20 and mpa in fig. 21 refer to the same bone; fig. 21 is inverted (by mistake).

\section{Plate XXVI.}

Fig. 1. Skull of Gavia ridibunda (first nestling), side view, partial. $\quad \times 3$ diameters.

Fig. 2. Same, from below. $\times 3$ diameters.

Fig. 3. End view of same. $\times 3$ diameters.

Fig. 4. Hinder part of mandible of same, outer view. $\times 3$ diameters.

Fig. 5. Same, from within. $\times 3$ diameters.

Fig. 6. Hyoid of same specimen. $\times 3$ diameters.

Fig. 7. Nasal labyrinth of same. $\times 5$ diameters.

Fig. 8. Transverse section of nasal vestibule of same. $\times 20$ diameters.

Fig. 9. A like section, further back. $\times 20$ diameters.

Fig. 10. Another section still further back. $\times 20$ diameters.

Fig. 11. A longitudinal view of the inside of the skull of second nestling (partial). $\quad \times 3$ diameters.

Fig. 12. A similar (perfect) section of the skull of fourth nestling.

Fig. 13. Section of alæ nasi of fourth nestling. $\times 20$ diameters.

Fig. 14. Section through ethmoid of fifth nestling. $\times 5$ diameters.

Fig. 15. Section near " notch" of ethmoid of fourth nestling. $\times 5$ diameters.

Fig. 16. Another section of same, through interorbital septum. $\times 5$ diameters.

Fig. 17. A like section, behind the fenestra. $\times 5$ diameters. 


\section{Plate XXVII.}

Hig. 1. Basis cranii of third nestling, from below. $\times 3$ diameters.

Fig. 1a. Alisphenoid of third nestling. $\times 3$ diameters.

Fig. 2. The same basis cranii, from above. $\times 3$ diameters.

Fig. 3. Side view of same. $\times 3$ diameters.

Hig. 4. End view of same. $\times 3$ diameters.

Hig. 5. Inner view of auditory region of the same. $\times 6$ diameters.

Fig. 6. Inner view of the other side. $\times 6$ diameters.

Fig. 7. Side view of skull of fifth nestling. $\times 1 \frac{3}{4}$ diameter.

Fig. 8. Upper view of same. $\times 1 \frac{3}{4}$ diameter.

Fig. 9. Lower view of same. $\times 1 \frac{2}{4}$ diameter.

Fig. 9a. Vomer of same, side view. $\times 4$ diameters.

Fig. 10. End view of same skull. $\times 1 \frac{3}{4}$ diameter.

Hig. 11. Part of side view of skull of the adult bird. $\times 6$ diameters. 
Trans Linn. Soc. Ser. 2. Zool.Vol. I. Tab. 20.

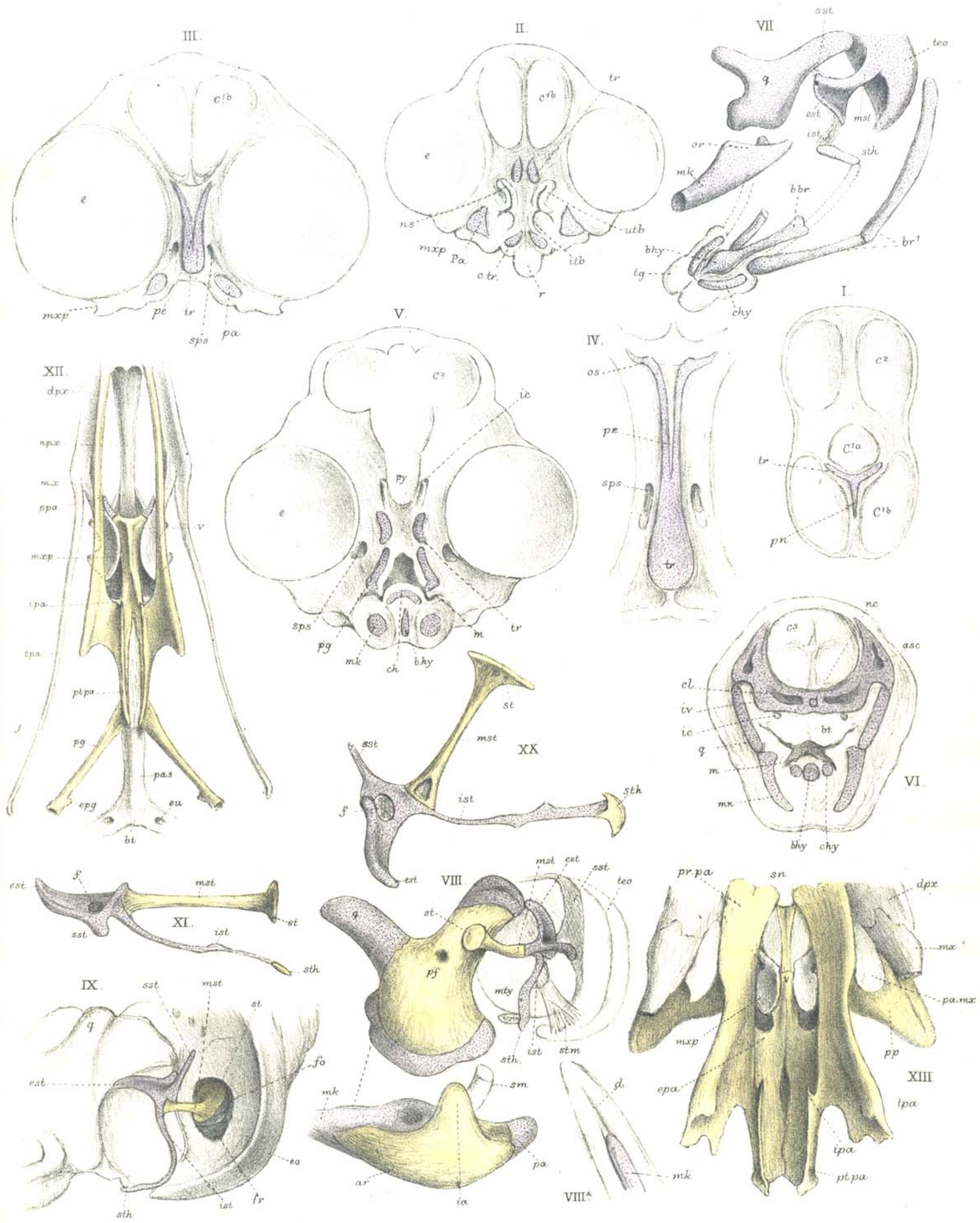

W.K.P. del ad nat. G. West lich

Chick and Coracomorphae. 
Trans.Linn. Soc. Ser. 2. Zool.Vol. I. Tab. 2I.
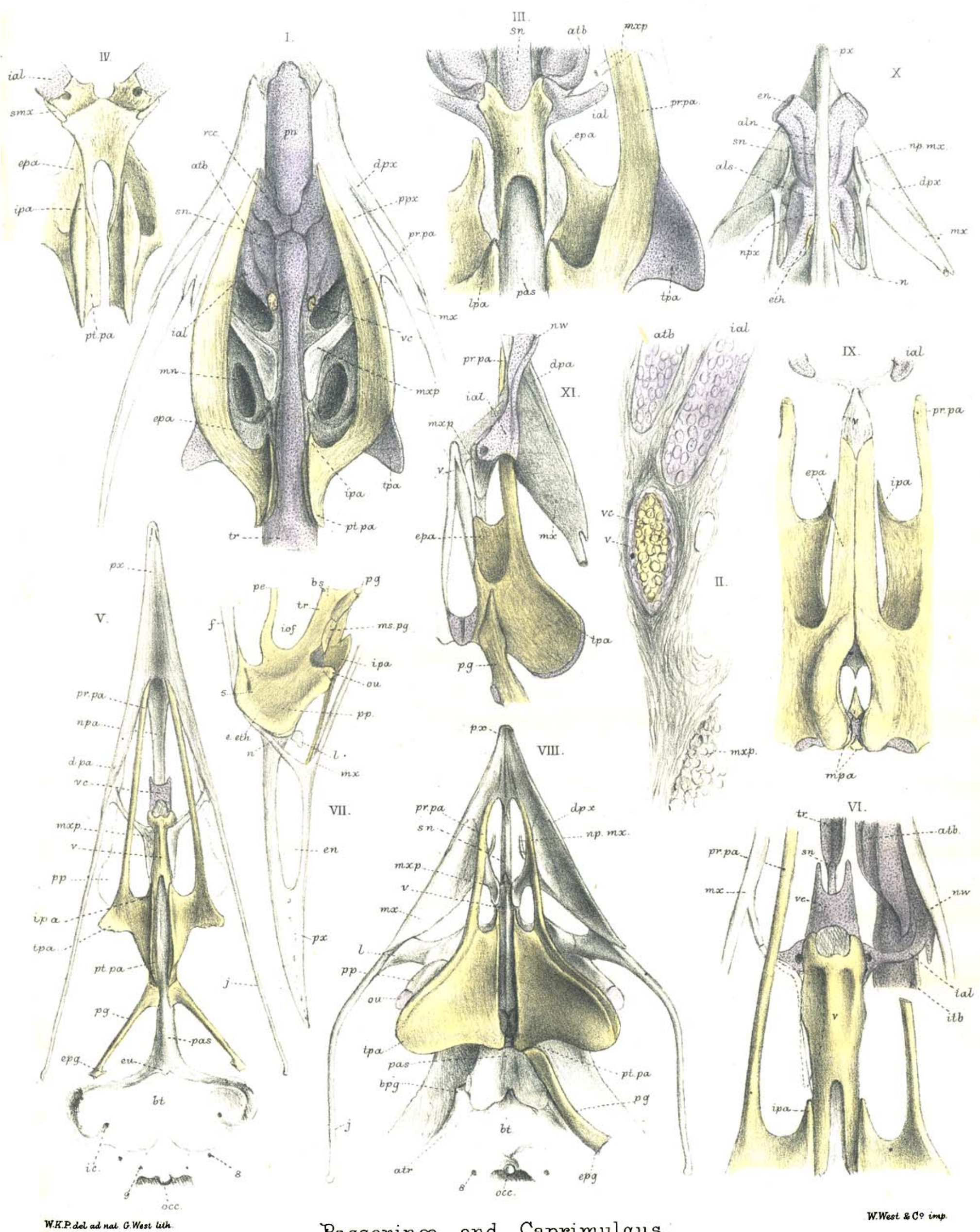


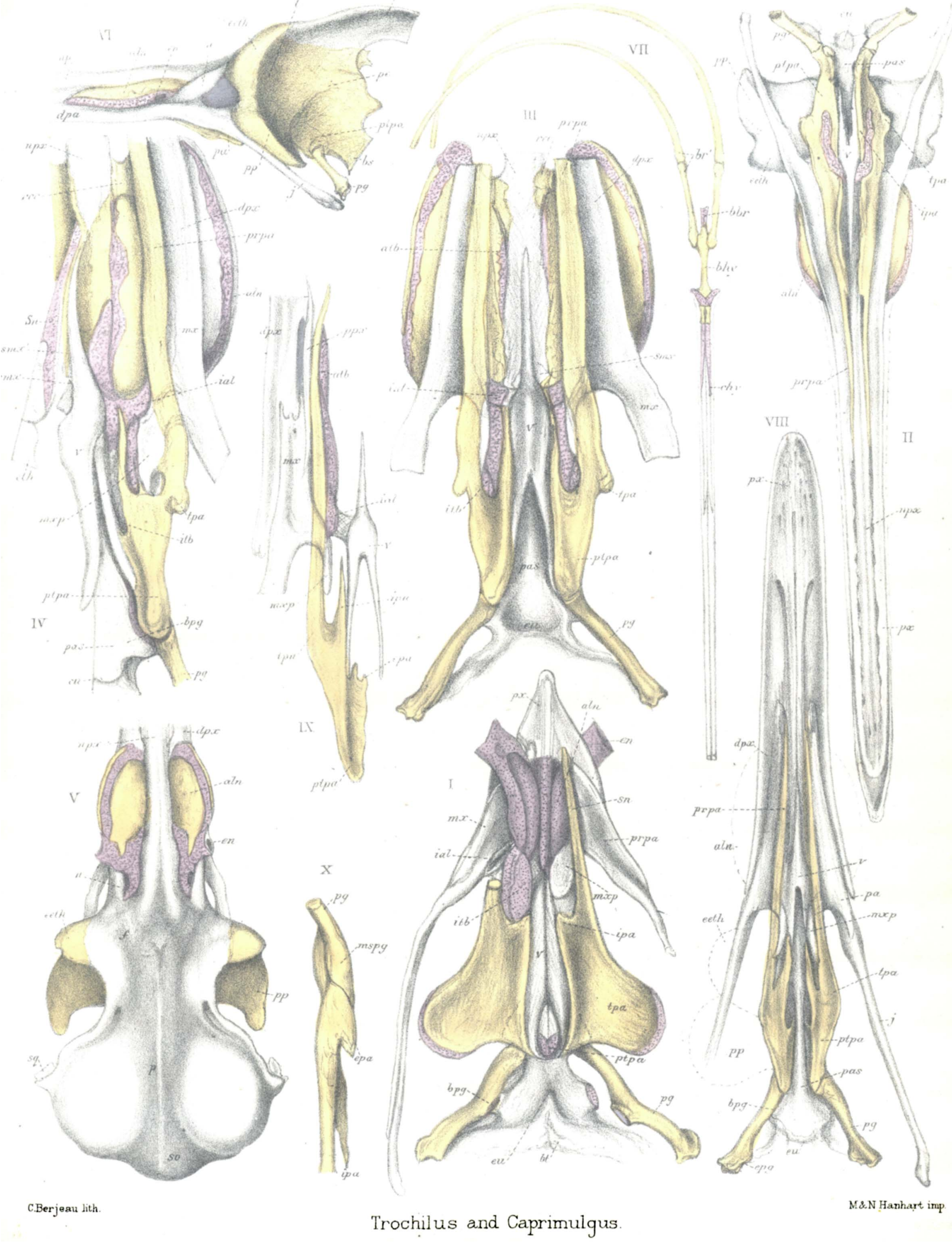




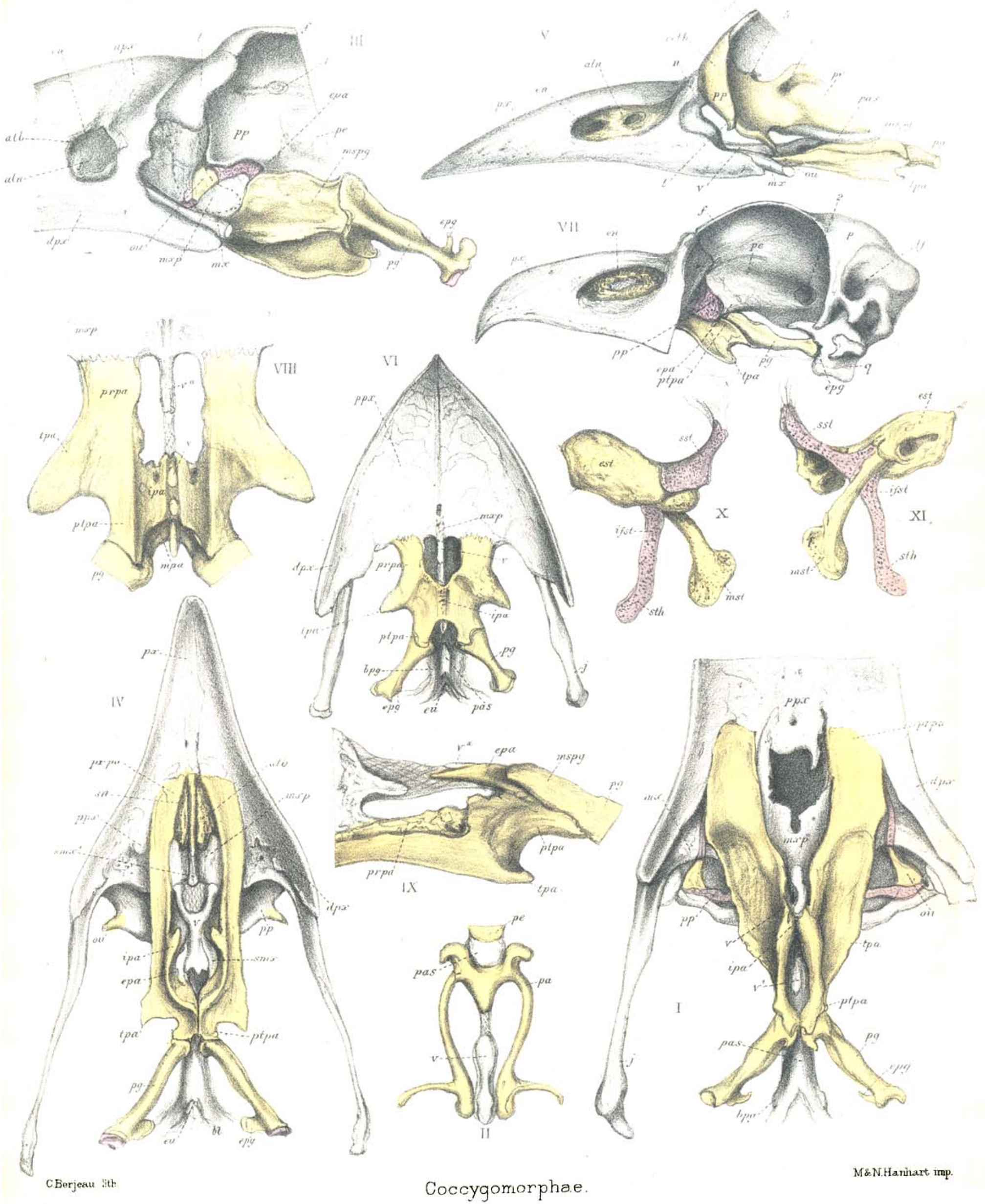


Trans Linn Soc Sek $2 \%$ om, Vou I Tab 24

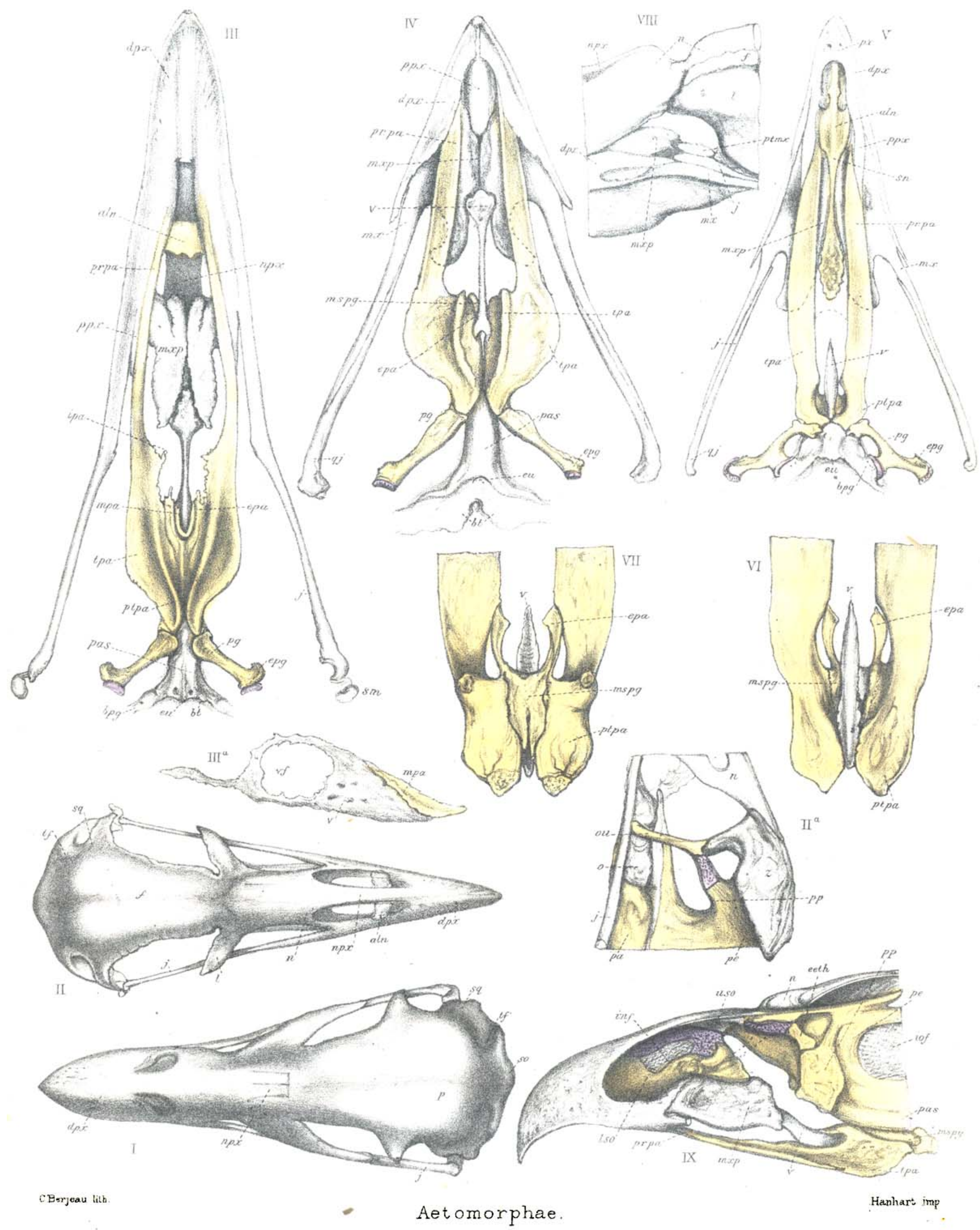


W.K.Parkosr del
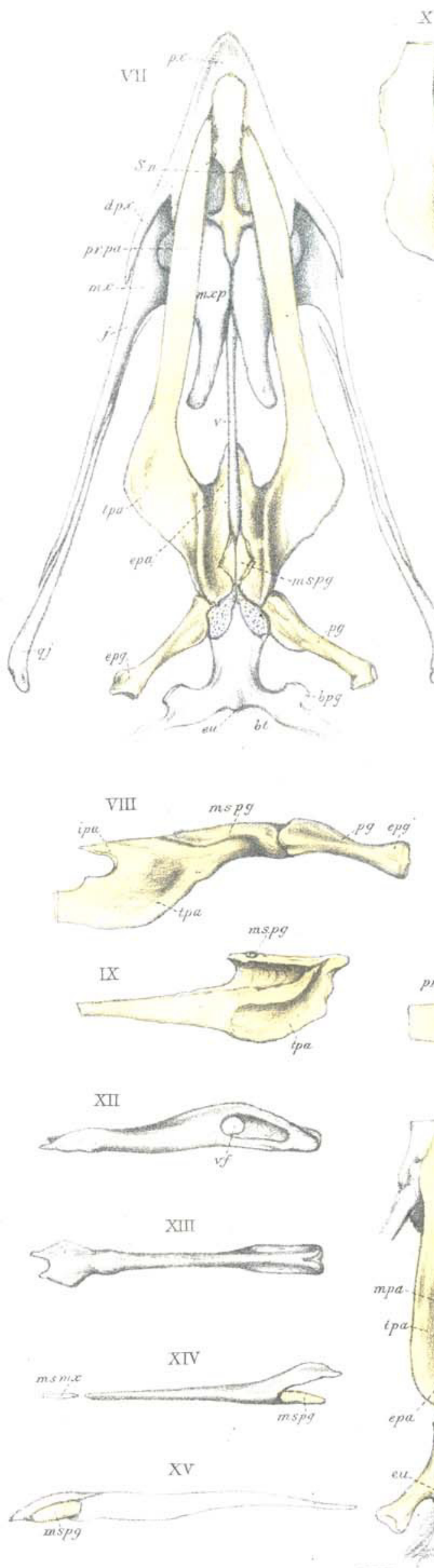

c.Berjeau lith.

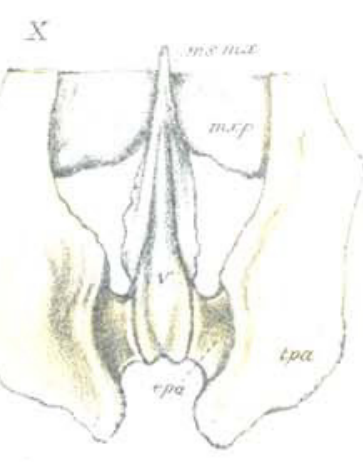

XI

Trans Linn. Soc. Ser 2.ZOod Vou, IT Tas 25
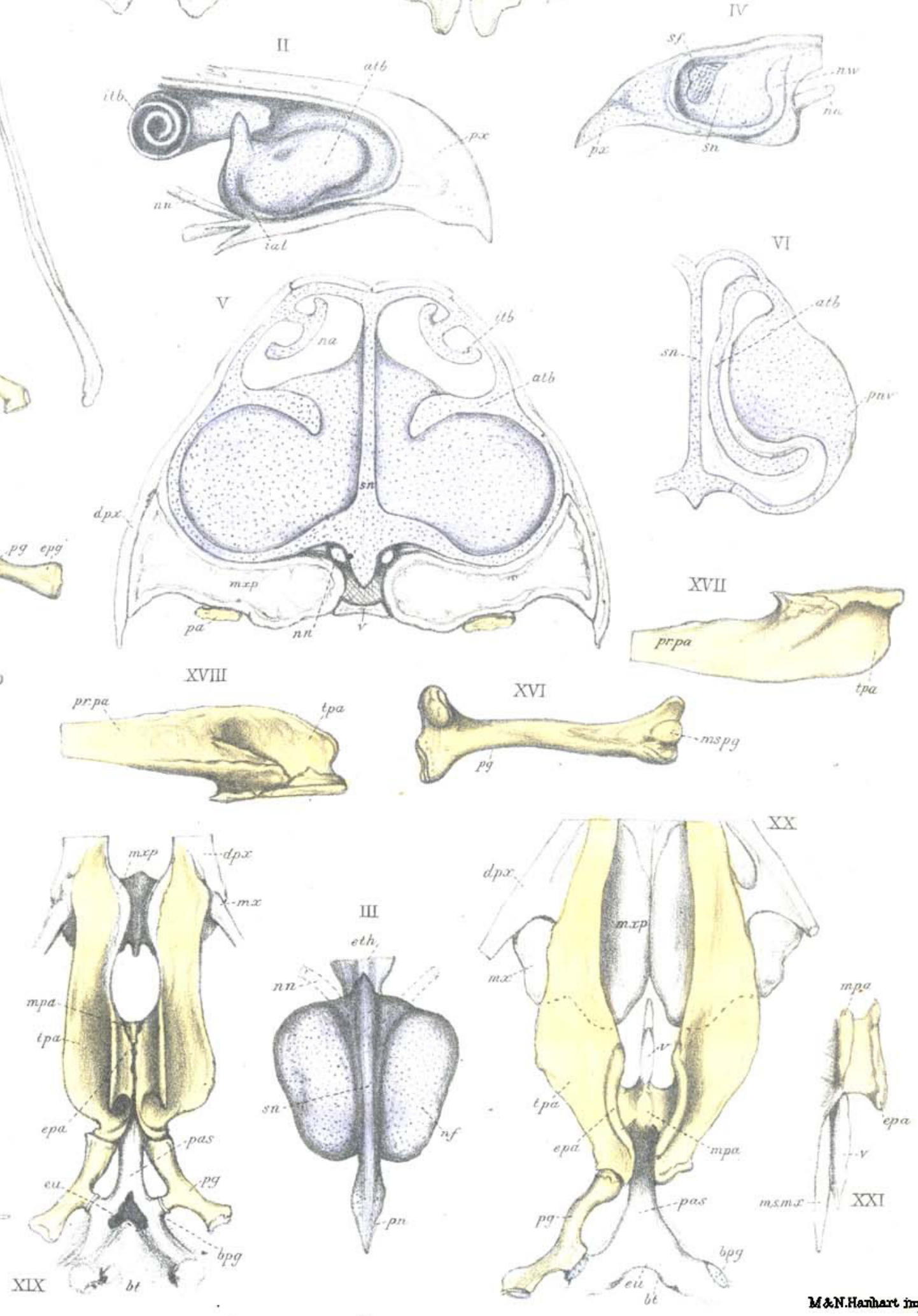

Aetomorphae. 

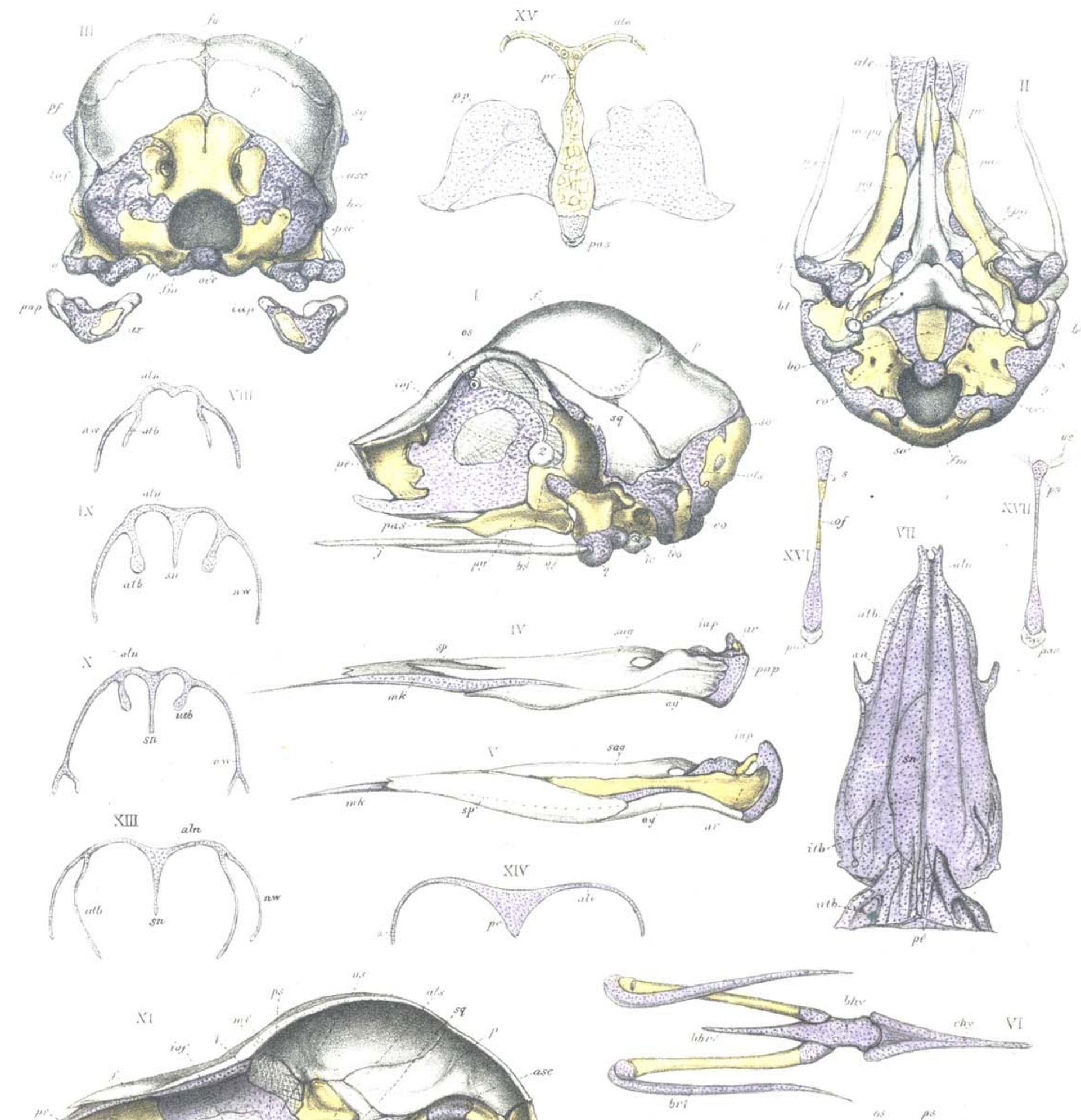

C.Bogean bil. 


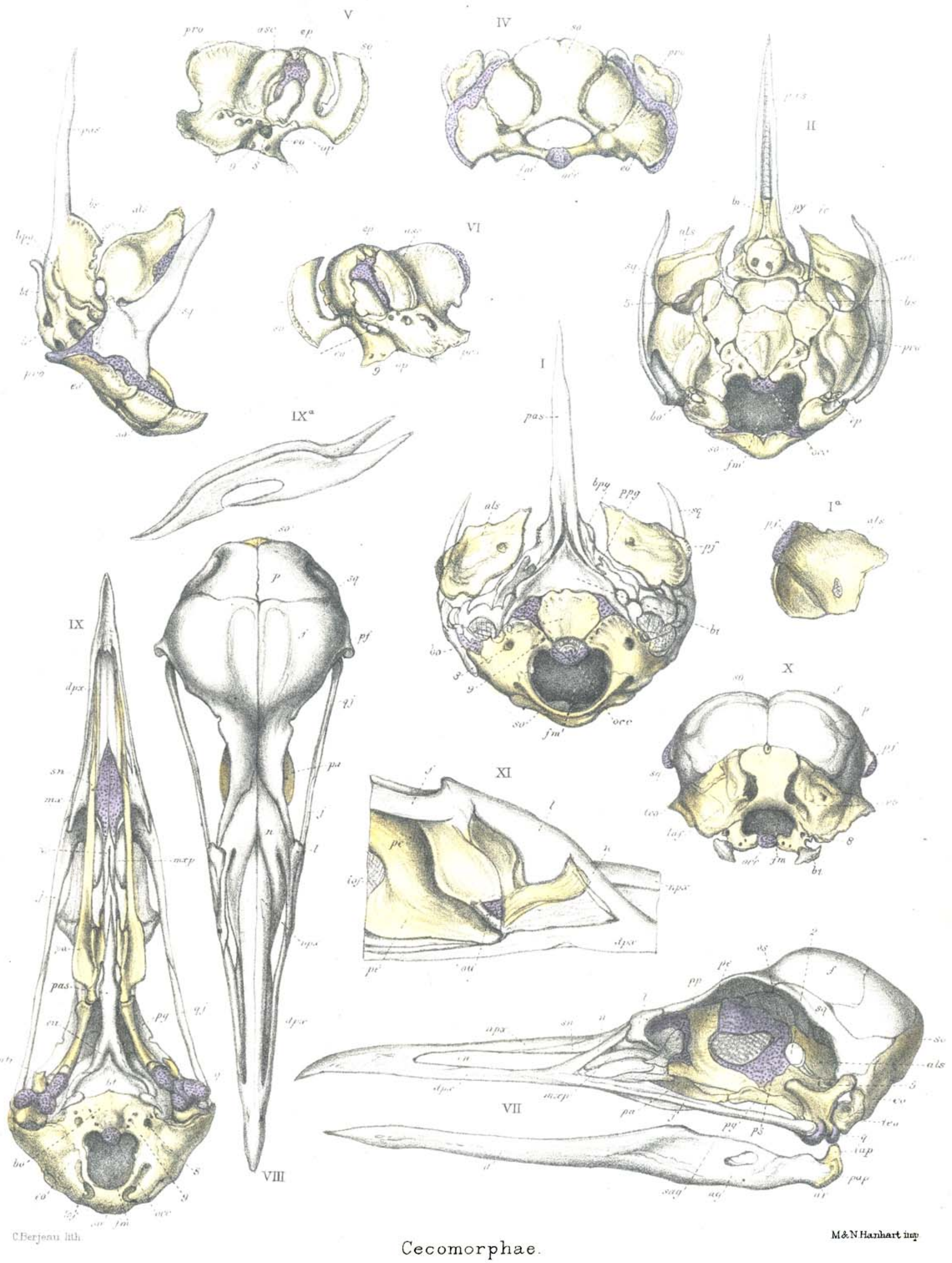

